\title{
Constraints in the IoT: The World in 2020 and Beyond
}

\author{
Asma Haroon \\ Department of Computer Science \\ COMSATS Institute of Information Technology \\ Islamabad, Pakistan \\ Munam Ali Shah \\ Department of Computer Science \\ COMSATS Institute of Information Technology \\ Islamabad, Pakistan \\ Yousra Asim \\ Department of Computer Science \\ COMSATS Institute of Information Technology \\ Islamabad, Pakistan
}

\author{
Wajeeha Naeem \\ Department of Computer Science \\ COMSATS Institute of Information Technology \\ Islamabad, Pakistan
}

\author{
Qaisar Javaid \\ Department of Computer Science \& Software Engineering, \\ International Islamic University, \\ Islamabad, Pakistan
}

\begin{abstract}
The Internet of Things (IoT), often referred as the future Internet; is a collection of interconnected devices integrated into the world-wide network that covers almost everything and could be available anywhere. IoT is an emerging technology and aims to play an important role in saving money, conserving energy, eliminating gap and better monitoring for intensive management on a routine basis. On the other hand, it is also facing certain design constraints such as technical challenges, social challenges, compromising privacy and performance tradeoffs. This paper surveys major technical limitations that are hindering the successful deployment of the IoT such as standardization, interoperability, networking issues, addressing and sensing issues, power and storage restrictions, privacy and security, etc. This paper categorizes the existing research on the technical constraints that have been published in the recent years. With this categorization, we aim to provide an easy and concise view of the technical aspects of the IoT. Furthermore, we forecast the changes influenced by the IoT. This paper predicts the future and provides an estimation of the world in year 2020 and beyond.
\end{abstract}

Keywords-Internet of Things; Future Internet; Next generation network issues; World-wide network; 2020

\section{INTRODUCTION}

The Internet of Things (IoT) is a next generation worldwide network that contains large number of interconnected heterogeneous physical devices, enlightened by [1].
CompTIA's research [2] and M. Swan [3] discussed the estimated ratio of objects connected to the internet to reach 50 billion in 2020. In fact, Cisco estimated the 11 trillion devices per year over 2025 [4]. This high-level connectivity supposed to be delivered by the IoT will clearly play main role in technical advancements, which will open new ways of productivity with more flexibility and customization. Technically, a device in specification of the IoT; is an object in real-time environment implemented with improved capabilities of computation and communication. Theoretically, the IoT is a durable connection of aforesaid objects or devices.

Nevertheless in the way to progress, the IoT faces some technical requirements such as functional requirements, nonfunctional requirements and design constraints categorized by [5]. Design constraints can be elaborated by the fact that smart things generally regarded as small sized physical devices connected with the Internet, face limitations in terms of IP numbers, packet size, packet loss and alternative paths for connectivity, throughput, power and supported complexity [6]. Furthermore, connected objects vary according to the functionality or purpose they serve. Elmangoush et al. [7] explained the heterogeneity and the challenges related to connecting devices that includes scalability, governance and lack of testbeds specifically for Smart Cities. The nature of each object varies according to their size, position and capabilities. 


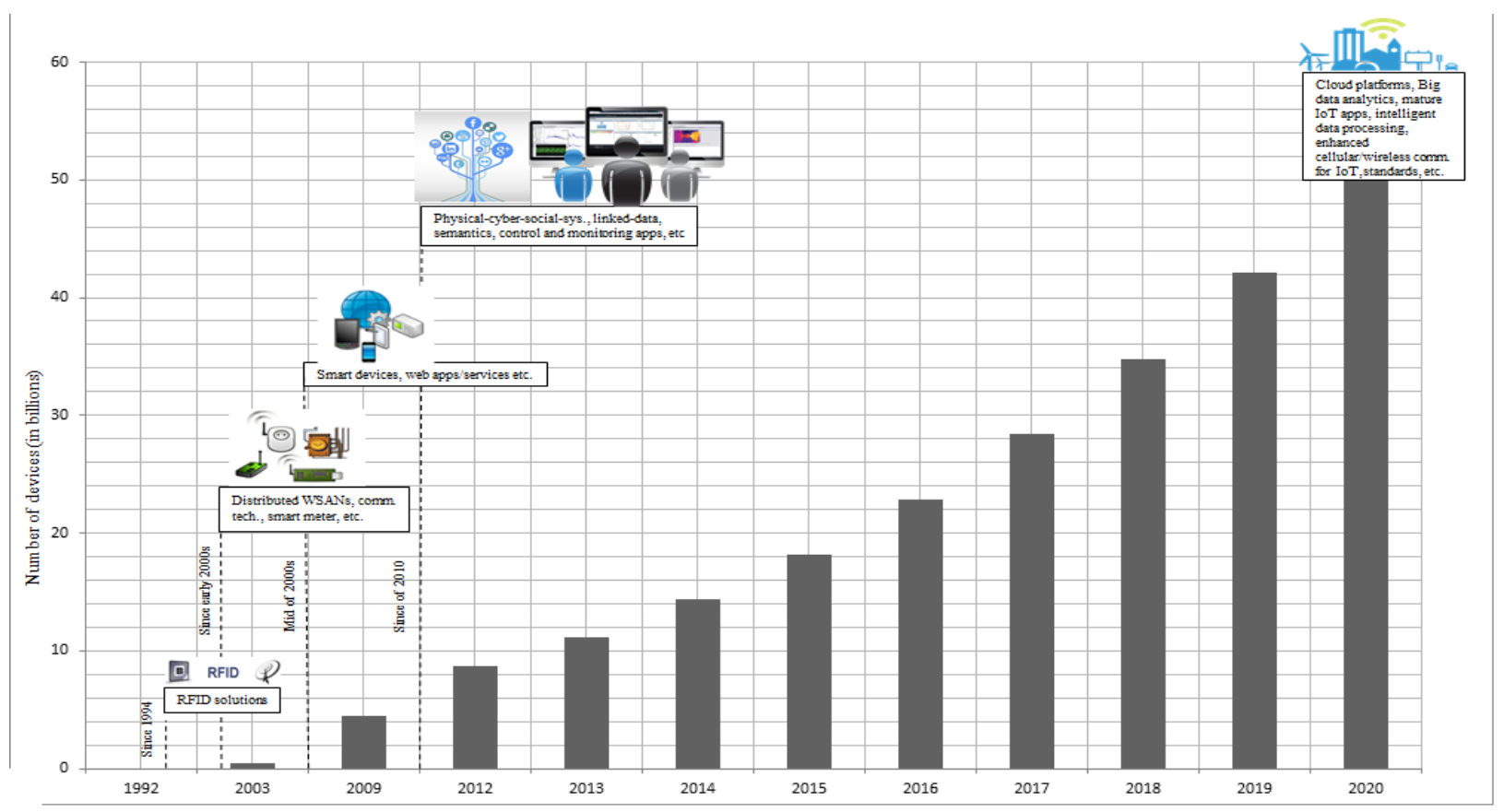

Fig. 1. Estimated number of interconnected devices obtained from [2][13]

In order to connect aforementioned objects in a network, a unique identification number such as RFID (Radio Frequency Identification) and sensor(s) for their continuous state sensing, are needed. RFID and sensors will enable the objects to interact but due to the huge ratio of objects and their variations creates the scalability and diversity of objects; a major hurdle. This will ultimately address the challenge to create a communication framework in such a way that can handle the scalability and variety of objects to achieve the intended applications that may encompass automation functionalities. Automation functionalities include sensing, acting, locating, identifying etc. analyzed by [8]. Figure 1 estimated the compound growth of the IoT that contains both ratios of existing and expected connected devices, along with their diversity. The curve in the Figure 1 also elaborates that the number of physical devices (in billions) per year is adversely increasing, that addresses both standardization and scalability challenge.

The IoT deployment demands to handle the challenges regarding constraint devices, scalability and diversity security issues. That ultimately leads to the requirement of enabling technologies such as hardware, software and algorithms, standardization techniques, network technologies, communication technologies, power and storage technologies, identification technologies, sensing technologies, data transference technologies, architecture and network relationship management technologies addressed by [9][10][1]. The major limitation involved in the deployment of the IoT regarding these technologies are analyzed by [7] [9][11][12] such as micro software, power and storage need, communication standardization, communication protocols, architecture design, security and network management. Multiple numbers of unique IDs per object need leads to the requirement of infinite number of unique IDs. However, this problem has been solved to some extent by IPv6. Micro operating systems are needed for unmeasurably small devices. Power and storage is the major requirement for small devices to sustain the reliable connectivity to the IoT. The necessary standardization techniques are required for the communication between diverse natures of devices in a network. Moreover, the considerable fact is that all of the devices or things are not connected to the Internet, all the time. In that case, there is a need to manage an alternative communication path. Therefore, architecture design also faces the barrier of devices' nature in this regard and checks for an alternative way to be connected. Security concerns and network management are also referred as major hurdles in the IoT.

The basic principle of the IoT technologies has been discussed in [10] is a combination of Sensor technology, RFID technology, Smart technology and Nano-technology. Aforesaid technologies are not new but with IoT advancement these technologies are been more focused and enhanced. However, there are lots of challenges with the addition of technical constraints in the way to deployment of the IoT that will be surveyed in this paper.

\section{Contribution of the paper:}

- This paper provides an analysis of recent major technical issues that the IoT is currently facing. The taxonomy for categorization of the IoT is provided.

- Moreover, a categorization of the technical constraints and their overlapping factors is also presented.

- The brief survey for technical restrictions of recent papers is presented in tabular form. It is positioned as a survey paper beneficial for wide range of audience such as business strategists, data analysts, researchers etc. 
- Furthermore, the technological advancements in the IoT along with their limitations and effects on society are provided to update the readers with recent trends.

- The open social challenges in future are also highlighted in the paper.

- The paper aimed to refine the basic principles needed to deploy the IoT.

- Moreover, the paper provided the estimation on the ratio of interconnected devices to the IoT up to 2026 and ratio of IT jobs up to 2020 based on previous estimations.

The rest of the paper is organized as follow. In Section II, the IoT technical constraints and enabling technologies are analyzed in broader perspectives. Most recent technological advancements related to the IoT are described briefly in section III to introduce the readers with the technological updates. Section IV is about performance evaluation of the technological advancement with their impacts on society and technical limitations. Whereas, in section $\mathrm{V}$ remaining open issues related to the IoT are shortly listed. Finally, to provide a short summary paper is concluded at the end in section VI.

\section{TECHNICAL CONSTRAINTS}

The Internet has been changed from computer-to-computer connection to ubiquitous Internet and now proceeding towards the IoT; that is everything is interlinked with every other thing, anywhere and anytime. It indicates that the IoT will provide bases to initiate a new technological phase soon (estimated in 2020), which will expose new means of opportunities in everyday life. Due to its vast applications, the IoT has been focused and new ideas have been proposed in this regard by many researchers in recent years. Figure 2 enlightened the major areas of the IoT that includes the IoT challenges, the top IoT enterprises, applications of the IoT services and the IoT solutions. However, the paper aims to specifically focus and explore the further categorization of its technical barriers highlighted by Figure 2. This section will analyze the technical constraints that include standardization and policies issues, hardware limitations, gateway systems challenges, middleware issues, the database management issues and security and privacy challenges as described below.

\section{A. Addressing and Sensing issue}

In the IoT, every object in real time environment, either it is a living thing or non-living thing, needed to be addressed by a unique identity. [11][12][19][20][21][22] analyzed the addressing and sensing issues in the IoT perspective such as IPv6 adaptation, automatic identification and configuration, participatory sensing, etc. Using sensor technology networks, it is obvious to have large number of nodes that must be addressable separately. On the other hand, the problem is the ratio of objects is far greater than IPv4 addressing scheme. Future estimations predict that it will increase to infinite number of devices or object instead of decreasing [2][4][13]. B. Stockebrand [23] claimed that IPv4 is already outnumbered and all of the IP addresses had been occupied. Therefore, IPv6 was defined by the means of 128 bit which will fulfill the demands of ever increasing IP addresses.
The famous claim about IPv6 is stated as it can assign address to every bit of this world but this scheme still faces the design limitations. The approach cannot be used in a scenario; if RFID tag identifier is 96 bits long. L. Atzori et al. [10], analyzed the methodology for this problem in which a separate agent is used for IPv6 IP address as an interface ID. As identified by [24], the transition to pure IPv6 is pretty challenging but it have more advantages over IPv4 scheme such as providing internal security and end-to-end user transparency with the addition of realization of addressing need. However, transition is not that easy, the IPv6 users' needs IPv4 side by side to use important resources and stay connected to existing connection. IPv6 requires a large amount of time to be fully functional as a standalone scheme. It shows that there is a huge gap for mobility support on technical bases. Therefore, mobility management is needed to be focused because of adaptability and scalability issues related to diverse nature of devices in heterogeneous environment.

The order in which address is been fetched correspondingly faces the drawbacks related to addressing technique. As Domain Name Server (DNS) is used for mapping domain name while fetching the IP address of host associated with specific given name but in the IoT, communication must take place between objects rather than hosts. The issue has been addressed by [20][25][26] and Atzori et al. [10] proposed that an Object Name Server (ONS) technique can be used at object level communication. In current Internet, the tag identifier mapped on the Internet Uniform Resource Locator (URL), and the desired information is fetched. However, Object Name Address (ONA) should work in both ways and vice versa in the IoT. It should be able to associate the information to a given RFID tag identifier and can also map on in opposite direction. The other issues in addition to addressing is; if the device is connected to Internet all the time then it can be addressable and its state can be sensed. However, due to heterogeneity of devices in the IoT, all of the devices are not connected to the Internet directly according to their nature or some critical security issues. In that case, the devices need some technique to be addressed indirectly and sensed to get updated by its state through some other medium.

\section{B. Networking Issue}

In networking, protocols play a critical role for connection and data transformation; as it can reduce the service integration time and cost [7][17]. Network protocol acts as a mainstay for data routing between outer world and sensors. The current Internet is using TCP protocol for transmission at transport layer, which is not feasible for the IoT due to its limitations. There are a lot of existing protocols depending upon different criteria for mobile networking but all of them have drawbacks making them impracticable for the IoT. So there is a need of protocol for efficient handling and processing of data. [9][10][11][27][28] analyzed the major issues related to TCP protocol which can be categorize as:

1) Connection Setup: TCP protocol creates connection first before initiating any data transmission which means, it is connection setup based protocol. It takes considerable time for 
creating connection before actual data transmission. It seems unnecessary and time wastage in case of the IoT because the amount of data and time for connection is considerable short.
Furthermore, connection is created between two terminals which is energy and resource taken, so it is not feasible.

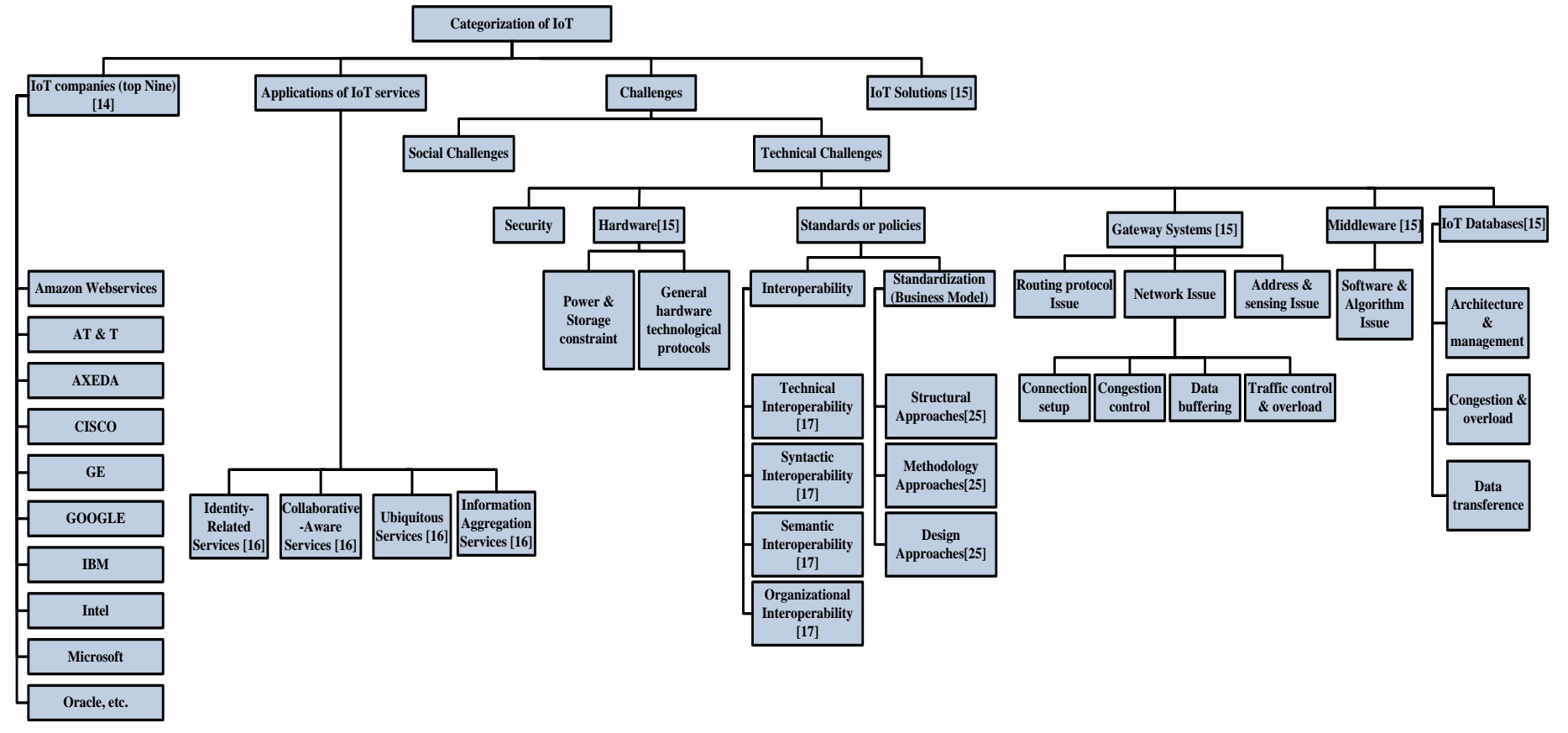

Fig. 2. Categorization of IoT obtained from [14][15][16][17][25] 
2) Congestion Control: TCP protocol is responsible for performing congestion control over both terminals during data transmission, which is not realizable in case of the IoT due to its heterogeneous nature. Most of the time, data to be transfer is of small size and the congestion control in that case is an overload. Moreover, the communication is done between different types of wireless networks and mediums. Congestion control in that scenario will decrease the performance. Thus, the TCP congestion control with its existing state is impractical in the IoT perception.

3) Data Buffering: TCP protocol stores data at both terminals to ensure the secure transmission of data. Subsequently, in case of any damage or loss during the transmission data can be resent. It requires buffers on both ends to store the data that will be very costly in term of both energy and storage for the devices which are small with low storage capacity and very limited battery life.

4) Traffic Control and Overload Issue: Traffic control in the IoT is another challenging task related to networking. It is a smooth transmission in term of traffic control when it is only between sensor nodes in wireless network. But it become complicated when sensors become part of whole network having heterogeneous purposes. In machine-to-machine (M2M) communication, the traffic control is totally different than human-to-machine communication. Moreover, unmeasurable number of devices involve in the IoT will also create overload traffic issues. Therefore, there is a need of characterization of network traffic which totally depends upon application scenarios. Furthermore, the existing network infrastructure is unable to address the high amount of traffic that is going to be generated in near future. Efficient protocol having advance levels of traffic handling and network management are needed to be implemented.

\section{Routing Protocol Issue}

Vehicle-to-Vehicle (V2V) communication is a type of distributed computation environment, which has huge number of nodes with variable and constrained network topology. However focusing on the importance of routing aspect in V2V communication, S. Agrawal and D. Vieira [11] discussed the two basic ways of routing. One is source routing: in which destination is already defined. Second is hop-to-hop routing: in which only next node address is known. Therefore, hop-to-hop routing is more suitable for $\mathrm{V} 2 \mathrm{~V}$ communication. Thus, the next best hop can be selected for routing during communication.

Routing protocols like Geographical Source Routing (GSR) use global positioning mechanism, which can cause path uncertainty and route fluctuation. On-Demand Routing protocol use flooding method that can create congestion problem because it sends data to all possible nodes. Various other existing routing techniques like Greedy Perimeter Stateless Routing (GPSR), Dynamic MANET on Demand, etc., have their own limitations and drawbacks. M2M is a key enabler for Smart Cities addressed by [7]. With the advancement of technologies, M2M will require consistent data routing due to the need of high data rates. This is a key challenge to create a reliable routing protocol having high speed transmission and low delivery delay time. 
Interoperability

OSI Model

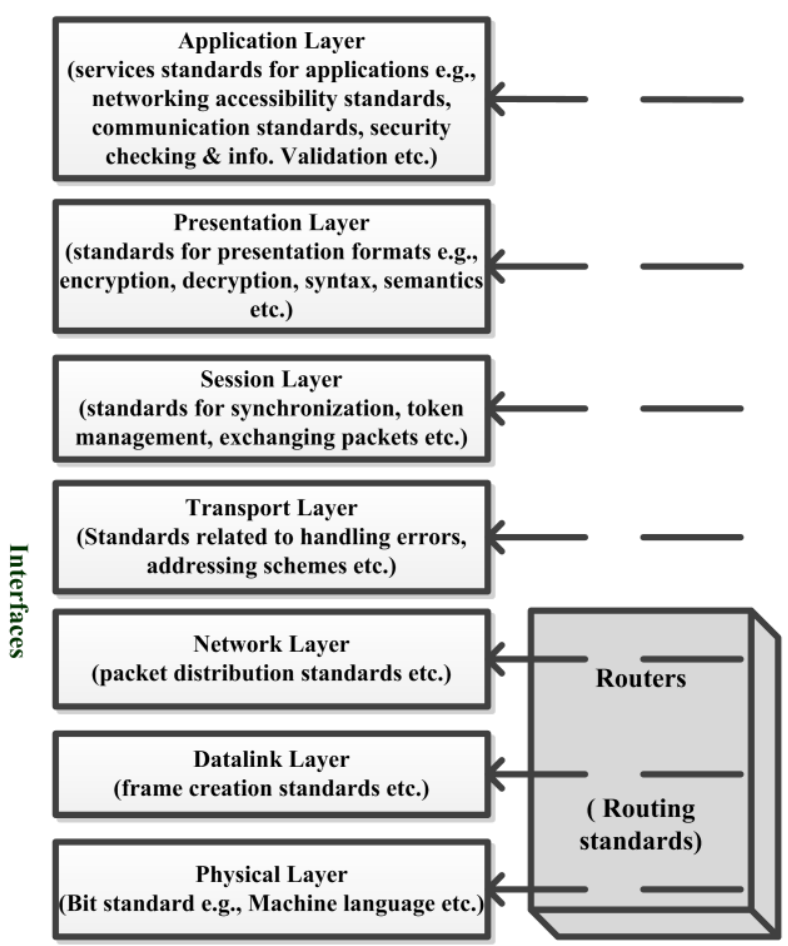

Host A

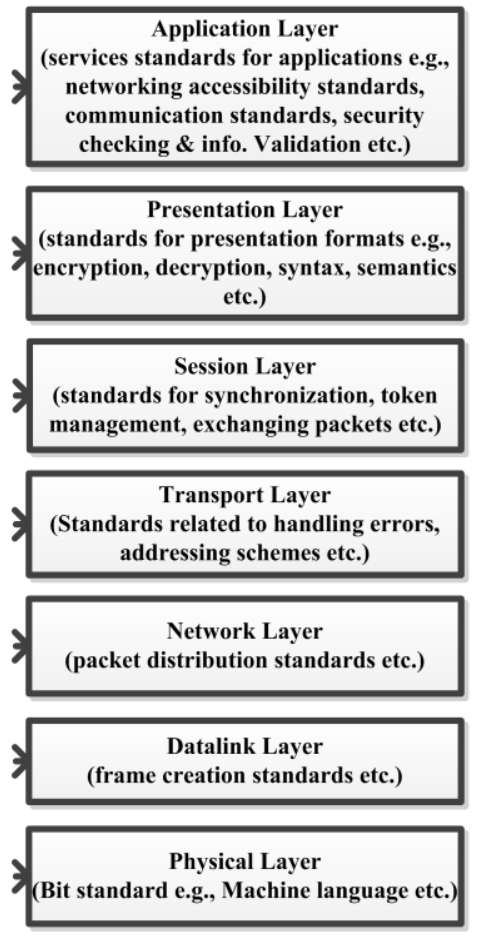

Host B

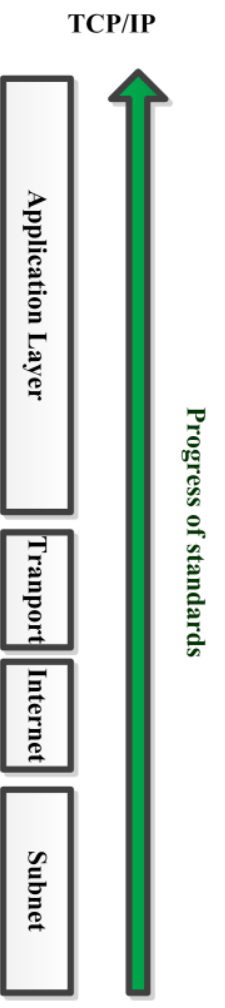

Fig. 3. Standardization level with respect to OSI model within interoperability obtained from [61] [62] [63]

\section{Standardization Issue}

The number of items in the IoT is extremely high. Therefore, issues related to representing information, storing information, interconnections, searching, and organizing information produced by the IoT will become very challenging [10]. Different approaches categorized as structural approaches, methodology approaches and design approaches have been proposed to achieve the business model discussed by [18]. In current Internet, application domains are separate, which is making business domains separate and ultimately not meeting the goal of the IoT. Thus, there is a need of standardization techniques to join all separated application domains in a sophisticated manner.

Diversity is an inherited characteristic of the IoT that leads to the major issue refer as interoperability. Whereas, standardization of technologies lead to better interoperability; as interoperability depends upon standards for functions and interfaces expressed in Figure 3. The gap that needs to address is lack of technical interoperability among diverse devices. W. Pollard [29] stress that in M2M communication scenario, standardization techniques provide a middleware to handle communication mechanisms, device management and reachability between end terminals. Moreover, it is necessary to follow standards for devices to work together on the same platform of the IoT. Otherwise the devices will not provide proper services to client. International Organization for
Standardization (ISO) provide family of standards, which are gaining popularity [17][30].

M2M communication is leading model toward the IoT but there is precise little standardization work done in this regard. The aim of M2M communication is to connect all the devices, sensors and their actuators abstracting communication techniques. The operation cost for $\mathrm{M} 2 \mathrm{M}$ communication is also addressable. Therefore, there is a need of optimized standard interfaces to be made for M2M communication in order to address interoperability and scalability issues related IoT. European Telecommunications Standards Institute (ETSI) is focusing on standardization techniques for M2M communication. Separate technical committee is launched for this purpose to increase the effort speed in European Telecommunications Standards Institute (ETSI). The common issues included are location, addressing, sensor networking integration, naming, charging, Quality of service (QoS), privacy and security, network management, software or application, and hardware interfaces for M2M communication standardization [7], [11], [28], [31], [32], [33].

\section{E. Software and Algorithm Issue}

There is a need of common software (in terms of new protocols) and algorithms to provide a middleware base independent of resources and networking function for the connectivity in different environments among diverse devices. 
J. Gubbi et al. [12] focus on creation of such distributive application development scenario to build a coherent application. That will support interoperable interaction among M2M communication over a network. In [34], it is focused that the distributive application should be containing selfmanageable properties containing self-optimization, selfconfiguration, self-healing to handle communication in different scenarios.

New micro operating systems are also required that can efficiently function for small devices in terms of energy and power. New password mechanisms should also be introduced to ensure the security and privacy during the communication. In this regard Service Oriented Architecture (SOA) approach has been followed by the IoT [10][21]. Service Oriented Architecture (SOA) allows decomposing the complex systems and monolithic system. This results in well-defined and simpler application development that follow standards during development ultimately facilitates components coordination among each other. This approach also gives reusability of software and hardware components. Perhaps, it also misses the solution to abstraction of details including devices, functionalities and capabilities details. To maintain the position on top levels CISCO claims to provide such software solution that will be highly focused on security concerns by [35].

\section{F. Power and Storage Constraint}

The IoT device is constrained by the entity which is in physically monitoring state and the position of the entity is frequently changing without access to power [7]. Most of the devices in the IoT are having considerable small size and are not fixed. Due to their size and frequently changing location property devices are not able to access the power all the time. So the low power consumption is universal constraint of the IoT. Either they use battery technologies or they can use some techniques for taking power from their environment using other devices. Therefore, there is a need of design in which such power consumption techniques or low power consumption schemes are made with long lasting life of devices. Another design issue to be addressed is a requirement of such modular approach that subtracts the need to make a separate chip for each and every application because it is not feasible to create a chip for each and every application. Such high modular approach will combine existing chips within size and power constraint. In [25], some theoretical low power circuit solution is proposed. Nevertheless, this area needs a lot of research and effort without which the IoT cannot be achieved.

\section{G. Architecture and Network Relationship Management Issue}

In the IoT perspective, devices have not been expected to sustain their positions. However, the reliable connectivity demands to address and sense the devices all the time. To address huge number of mobile nodes in a world-wide network is also referred as major scalability issue. $[7][12][10][19][36][37]$ analyzed the need to address architecture and network relationship management issue. N. Meghanathan, S. Boumerdassi, N. Chaki, and D. Nagamalai [38] emphasized the need to build architecture with such efficient mechanism that can discover all sensor resources and can register and update new sensing systems in wider network. In [39], the major challenge to the IoT is triggered that "Who monitors the monitor?". The IoT is integrating the heterogeneous devices into already defined networks, which is particularly advancement for industrial revolution. The problem is; if the information from machines are stolen or fetched and used for purpose by unauthorized person or entity. The IoT will never stop evolving and ratio of objects will increase with the time. With more devices connected to the IoT will raise the amount of data that required to be managed efficiently. Moreover, it is not possible to cover each and every scenario of the IoT. By customizable sensor technologies the things are able to be monitored by a specific location but the things can be monitored not the devices.

Intelligent networks are needed to be created which can control and monitor each other independently. Another issue pointed by CISCO [40], is data collection especially in Smart Grids Networks, which clearly maps to scalability issue. Other issues related to networking management include Closed-Loop Functioning and Network Resource Preservation. There is a need of such architecture which will able to handle these sort of Ad-hoc networks using different Network technologies (wireless, fixed, mobile etc.), equally and efficiently. Whereas, in [40] CISCO clearly understands the marketing progress in IoT so it is working deliberately hard and proposed new technology named "FOG computing" as a solution to prominent problems. Its practical implementation is estimated up to 2018 by CISCO. In[41], TELIT as a service provider claims to be an IoT global enablement partner. Its focus is on Mobile Network Operation Management and security. 


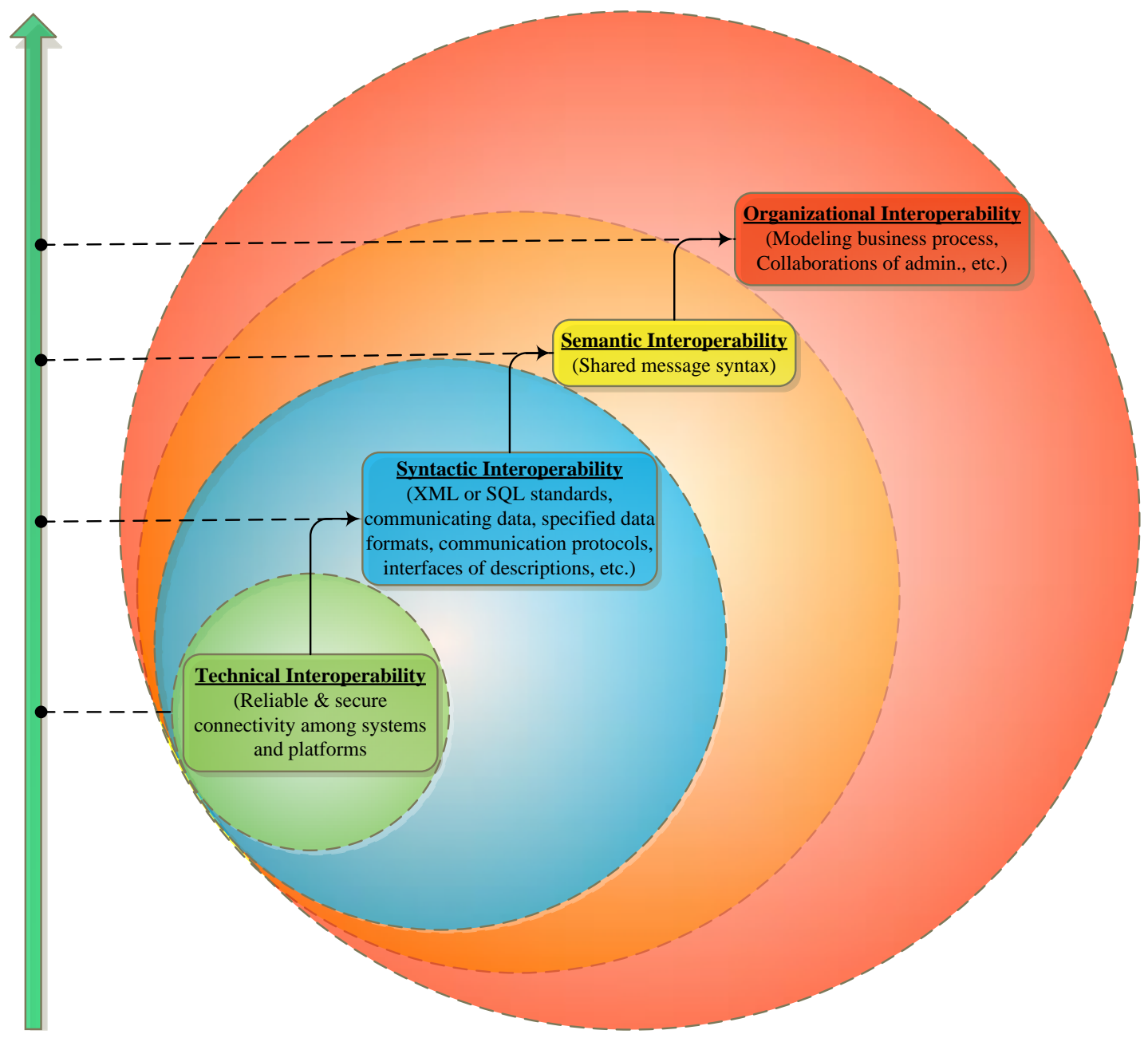

Fig. 4. Bottom-up Layered approach of Interoperability

\section{H. Hardware Issue}

Field of Nano-technologies has been quite evolved in recent years but still some software are very large to be handled on such level (in the IoT perspective) e.g., Linux with all features. Furthermore, the hardware issue with power and storage constraint also required to be managed. RFID technology has been researched a lot in this regard, which make system noticeable of small size and low cost [10][22][39][42]. It provides high radio coverage area. RFID sensor network can support computing data, communication and sensing devices abilities in an inactive system. In a realtime critical environment, IoT also needs back-end sensors, networks and infrastructure in case of any failure occurs in the regular IoT network. Now the IT business communities are more focusing on hardware development for the future market competition. CISCO [35], one of the competitive organizations; is claiming to produce such open hardware solution that will be able to work with other hardware components or devices. This means that these hardware solutions will be perfect solution for networking environments and it will provide sound functionality while connected to other devices. Moreover, there hardware and software solutions will be focused on security as security is the major issue in IoT. Such hardware solutions are needed for future
Internet, which can handle all constraints mentioned above and new undiscovered problems because practical implementations are needed to test the IoT environments, which is currently not implementable due to certain limitations for example Smart City.

\section{Interoperability}

In [17], many organizations including ETSI (European Telecommunications Standards Institute), TIA (Telecommunications Indus- try Association), ITU-T (International Telecommunication Union), OMA (Open Mobile Alliance), GISFI (Global ICT Standardization Forum for India), CASAGRAS (coordination and support action for global RFID-related activities and standardization), CCSA(China communication standard association), etc. are specified. These organizations are specifically working for interoperability issue in IoT and M2M communication. M2M provide base for the IoT architecture as it describes the serviceable components of IoT. Interoperability is also addressed in [30][24][25][45][46] as one of the major key challenge. In [17], different levels of interoperability has been defined.

Figure 4 presents a bottom-up approach, which can also be described as layered approach. Each layer is dependent to the 
layer below in some scenario, for example, syntactic interoperability is only possible, if technical interoperability exists so the syntactic interoperability will be the next step when technical interoperability is already implemented and so on. In [17], it is analyzed that there are two major issues regarding technical interoperability. One is the lack of complete reference architecture and other problem is the lack of technical interoperability estimation scope. Whereas, [47] claimed that technical interoperability can be achieved as technology progressing rapidly but business and semantic interoperability is the more challenging issues. Moreover, [48] stated that in technical area professionals needed to work with business area professionals as partners to achieve the IoT. Business interoperability is the most difficult challenge of all other interoperability.

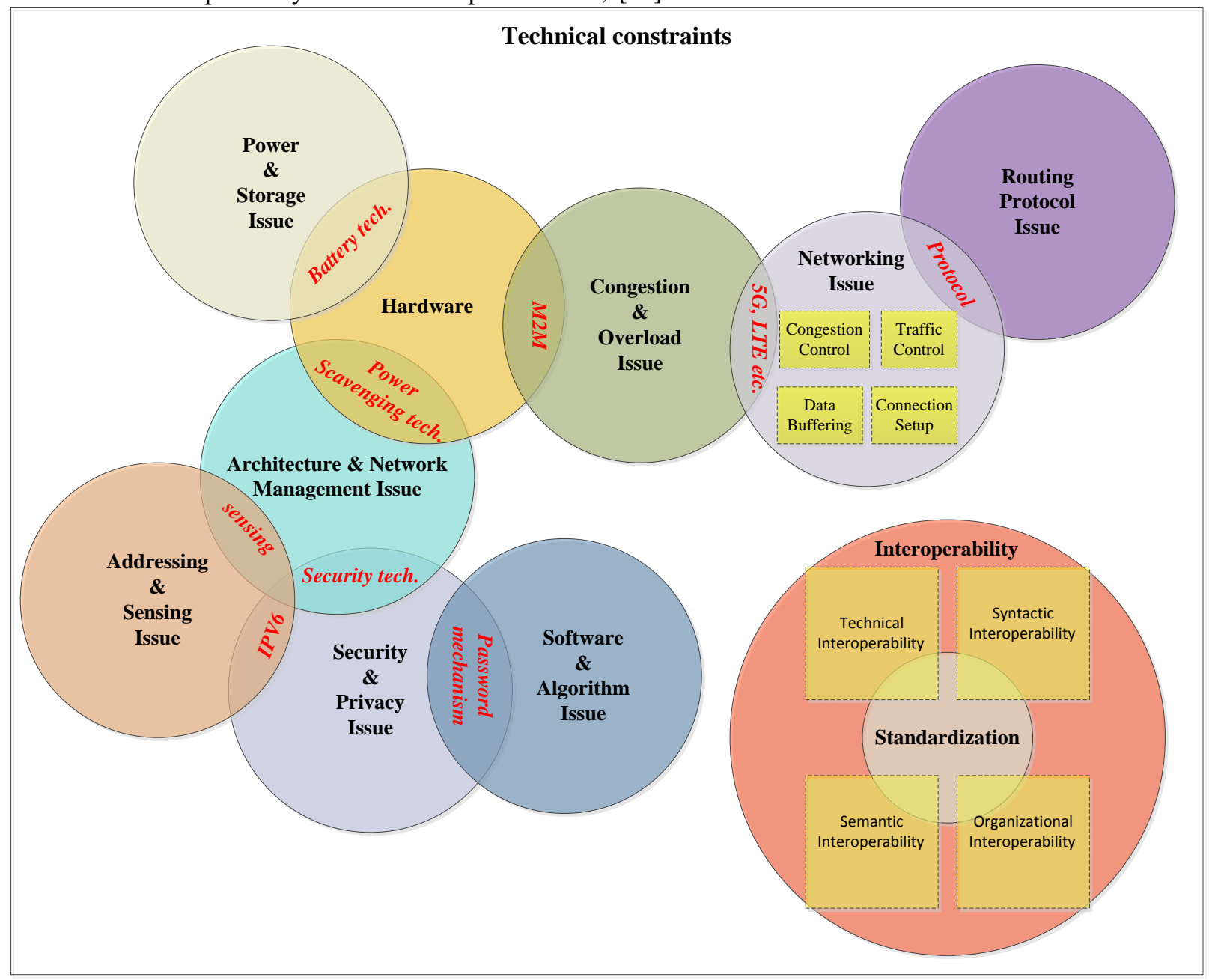

Fig. 5. Overlapping Technical Constraints

\section{J. Congestion and Overload Issue}

Congestion problem occurs when simultaneous messages came from multiple devices eventually leads to extreme overload situation which causes huge effect on network (3GP) which affects the network performance and leads to network failure. This situation can be seen in M2M and V2V communication and it has been researched by [5][6] related to the IoT. The congestion can also be occurred due to server or application malfunction. In [41], solution has been analyzed of congestion and overload issues, which can be resolved by LTE-advanced or existing technologies like LTE high bandwidth networks. One solution to this congestion control is to specify the time duration for connection. Devices can only connect to network when there is no overload and if the network is overloaded then disable all other connections.
Second solution is to reject the connection from devices which create congestion problem.

\section{K. Security and Privacy (Data transference issue)}

Security and privacy is one of the most important hurdle of the IoT and it has been recently researched exhaustively by [49][9][50][20][51]. As security and privacy is a completely separate research area but indirectly collaborates with technical constraints therefore this survey does not focus on it but instead it just delivers the main idea. Technically, the IoT will not be applicable until or unless people tend to accept it. And this acceptance is correlated to the guarantee of their security and privacy. Data could not be collected in anticipation of the mistrust of people towards the Internet is cleared. However, the uncertainty of the security and privacy is due to the dark side of the IoT infrastructure. The future 
internet will not only affect the IoT users but even non-users will also be targeted, indifferent to the todays Internet scenario.

The digital storage cost is tremendously decreasing, that result to store the information once generated to unlimited time, also included the fact about user's forgetting attitude towards digital data. Ultimately the IoT is providing an environment of great risk to privacy and security by integrating all of this digital data into world-wide network. Privacy and security can only be ensured if a user has fully control over his/her information. A user must know that what personal data is collected, who is collecting, where it is processed and when it was collected. Furthermore, the personal data should only be used by authorized service providers e.g., authorize medical organizations, authorize research institutions, authorize management systems, etc. Moreover, the data should only be stored for restricted time limit under severely need base scenarios otherwise it must be destroyed immediately. But this type of control is nearly impossible in sensor networks and the management authority is also difficult to define for this sort of control. Security constraint has also been focused by [6][18][26][52]. The data transference techniques are not able to control such level of security breaches due to technical limitations related to networking and middleware. Thus, there is a need to create such sort of data transference techniques that will not only handle high-level of security but also ensure authentication and data integrity.

The technical constraints explained in this section are overlapping each other but defined at some level of boundaries. Figure 5 highlighted this fact with the overlapping circles of constraints and red text in shaded areas in the overlapping regions. These overlapping regions show the interconnected behavior of the IoT technical constraints.

\section{Most RECENT TECHNOLOGICAL DEVELOPMENTS}

In this section, the most recent technological developments in the IoT perspective are briefly described. In [53] many recent technologies and their impact on daily lives have been analyzed. Customized services that matched for situation using location information, is implemented by using personal preferences and locating the person position. GPS and Google mapping is used to achieve the function. It can be used for different perspectives e.g., best nearby restaurants, hospitals, institutes, etc. With the use of smartphone, a person can be notified in nearby best restaurants, hospitals, institutions, service providers (Software houses), etc. according to personal preferences and customer or user received reviews.

The traditional Internet converts the world into a form of village but the future Internet is providing services entirely eliminating space constraints. It includes advancements such as smart city, precautionary maintenance system, remote electronics control service, etc. [53]. All electronics and devices are connected with social networking service (also called as social networking site or SNS). It manages real-time statistics e.g., temperature, speed, air pressure, and vibration. The statistics are then analyzed and prediction using data analytics are produced. In Smart City, the integrated CCTV control center recognized instead of human monitoring. If there has been a crime, the system guesses and investigates the suspect's expected escape routes. System notifies the police's mobiles with the related information. It minimizes the crime rate and prevents lives loss or additional damages. In precautionary maintenance system, engine failures in aircraft lead to flight delays due to repairs. This ultimately results in customer complaints at the end, and may even cause major accidents with casualties. For this reason, Rolls-Royce adopted a remote monitoring service by assigning sensors to their aircraft engines. In [46], Rolls-Royce also provides the preventive maintenance service, which eliminates probable intimidations based on its estimations. It could also lead the aircraft engine market by switching from a 'sales business': selling and supporting engines, to a 'service business': charging the rates on service used. Remote electronics control service provides Home Chat facility with the Electronics and mobile devices connected to home appliances. It enables a person to handle home appliances remotely. 


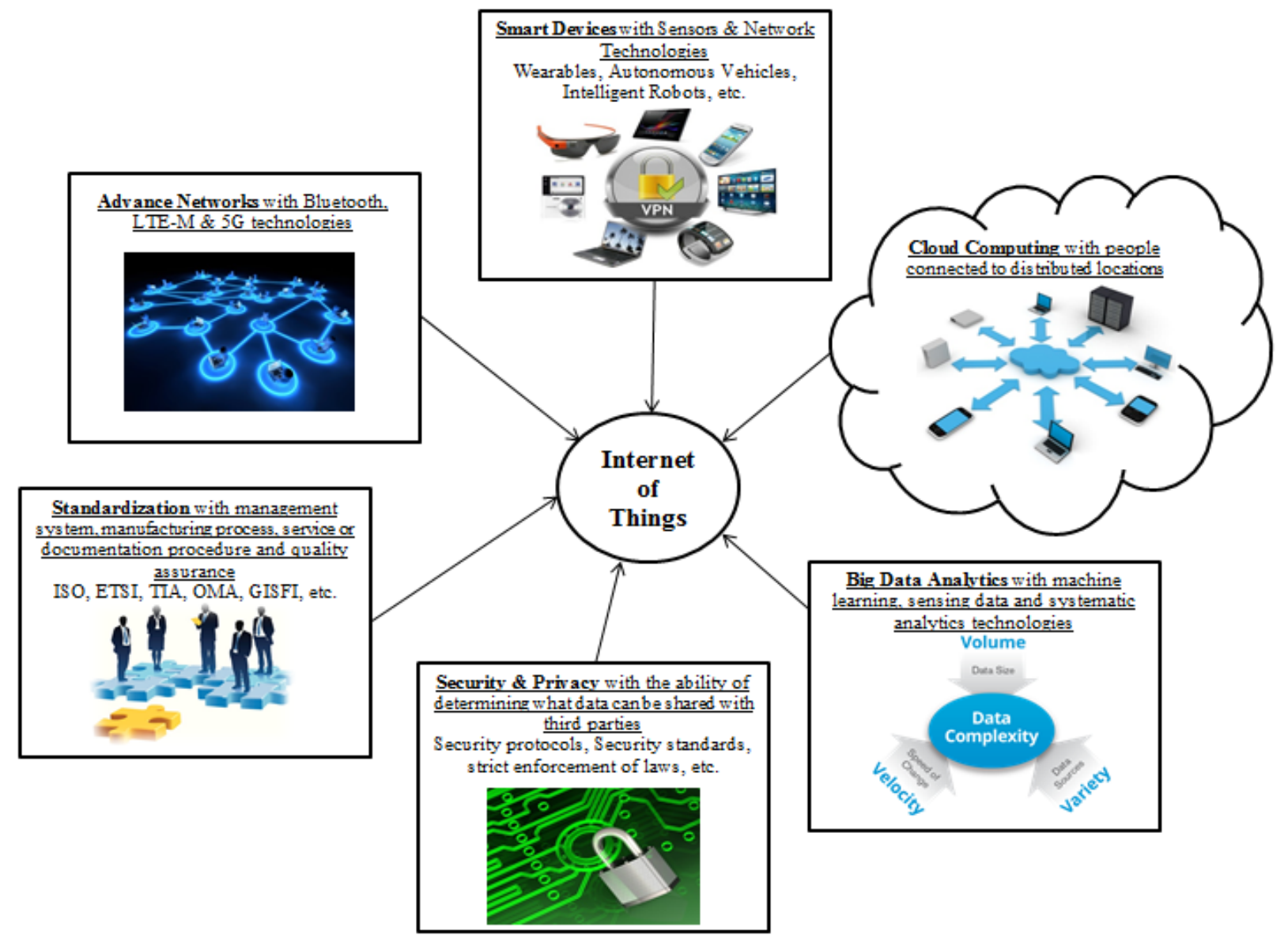

Fig. 6. Six key factors necessary to deploy the IoT

Optimized management systems with data-based computerization analyze data analytics. GE rail network optimization solution is an implemented system [54]. It reduces extra operational costs (such as a subway train slowing down to wait for the train, in front of it to be removed) because energy and time is needed to reduce speed sharply in keeping a safe distance from other trains and to recover speed. Railroad management is an implemented example of it. The aim of this system is that trains ride smoothly under a systematized system, which results in reducing extra operational costs. GE began monitoring all trains' operational status and locations to automatically determine the right speed for the schedule, with their rail network optimization solution and movement planner system. This change has improved their train speeds by 15 to $20 \%$ compared to the average [53].

Uber service is like the traditional call for taxis from the company. 'Transparency' is the key feature in the request process that results in privacy maintenance explained by [53]. Passengers have easy access to nearest available cab/taxi whenever and wherever they want. Personal information of the driver / passengers and reviews from previous passengers are maintained that ultimately provide better customer experience. Moreover, negative reviewers can be constrained from the Uber service for avoiding bad experiences. Smart Payment provides easy use of service.
LittleBits kit, is a hardware set for toys developed in the U.S. [55]. It is an electronic circuit development kit that enables people to develop the IoT lacking any low-level knowledge of development but only with little concept of Input and Output. This is one of the products and services that help even beginners to implement the IoT. The purpose of LittleBits is to provide a system where anyone can build, prototype, and learn about electronics. Each modular component is labeled with a purpose. By chaining them together with their magnetic links more complex circuits started to form. Hooking and unhooking are simple as magnets connect to each module. LittleBits kit can control all ranging from sound to real moving motors, powered by either a $9 \mathrm{~V}$ battery or a power supply [56].

In Smart School [57], ongoing project involves varieties of multimedia equipment such as electronic pens, digital textbooks, tablet PCs, multimedia, etc. Using these high-tech instruments and integrating them into the system, with highlevel connectivity desire functionality is achieved. Smart school based on basic key features of Smart Classes, Smart Information and Smart Management. In Smart class, an Integration of E-Learning environment is achieved by integrating High-Tech equipment. Smart card includes Multifunction (e-attendance, access control, and e-locker) and scalability as an e-cash service. Smart information provides various information such as school affairs, building locations 
etc. and increasing security. Smart management remotely monitors and control devices/equipment and automated trouble warning. With such an integrated system, people in remote locations can share their judgments, heighten the quality of teaching resources, and make smart teamwork classrooms for a more proficient class.

TABle I. Technological Advancement in the Iot and the Performance Evaluation

\begin{tabular}{|c|c|c|c|c|}
\hline Technology Advancement & $\begin{array}{l}\text { Development } \\
\text { Techniques }\end{array}$ & Category & Effect/Benefits on daily life & Limitation \\
\hline $\begin{array}{l}\text { Optimized management } \\
\text { systems with data-based } \\
\text { automation } \\
{[53]}\end{array}$ & $\begin{array}{l}\text { Integrated CCTV } \\
\text { control centers } \\
\text { Sensors and State } \\
\text { controlling electronic } \\
\text { devices } \\
\text { Data analytics }\end{array}$ & $\begin{array}{l}\text { Software } \\
\text { Hardware } \\
\text { Database } \\
\text { management } \\
\text { system }\end{array}$ & $\begin{array}{l}\text { Organized system } \\
\text { Reduce extra operational costs } \\
\text { Improved train speeds by } 15 \text { to } 20 \% \text { compared to the } \\
\text { average [53]. } \\
\text { Network Optimization Solution and Movement Planner } \\
\text { System. }\end{array}$ & $\begin{array}{l}\text { Complex data } \\
\text { analytics } \\
\text { strategies, } \\
\text { expensive }\end{array}$ \\
\hline $\begin{array}{l}\text { Customized services that } \\
\text { suited for context using } \\
\text { location information [53] }\end{array}$ & $\begin{array}{l}\text { GPS } \\
\text { Google mapping }\end{array}$ & $\begin{array}{l}\text { Software } \\
\text { Database } \\
\text { Application }\end{array}$ & $\begin{array}{l}\text { Notifications for nearby best service providers } \\
\text { Personal preferences and customer or user received } \\
\text { reviews. }\end{array}$ & $\begin{array}{l}\text { End user info can } \\
\text { be wrong }\end{array}$ \\
\hline $\begin{array}{l}\text { Creating new values by } \\
\text { connecting objects [53] }\end{array}$ & $\begin{array}{l}\text { GPS } \\
\text { SNS } \\
\text { Data analytics }\end{array}$ & Application & $\begin{array}{l}\text { Transparency } \\
\text { Improved customer service experience } \\
\text { Smart payments and ease of access } \\
\text { Avoid and control negativity to prevent bad events }\end{array}$ & $\begin{array}{l}\text { Started to destroy } \\
\text { the current market } \\
\text { rapidly }\end{array}$ \\
\hline $\begin{array}{l}\text { Services eliminating space } \\
\text { constraints [53] }\end{array}$ & $\begin{array}{l}\text { Integrated CCTV } \\
\text { control centers } \\
\text { Sensors (temperature, } \\
\text { air pressure, speed, } \\
\text { vibration, etc.) } \\
\text { Social networking } \\
\text { service ( SNS) } \\
\text { Data analytics }\end{array}$ & $\begin{array}{l}\text { Cyber-physical } \\
\text { systems } \\
\text { Software } \\
\text { Management } \\
\text { Application }\end{array}$ & $\begin{array}{l}\text { Smart city: } \\
\text { Replacement of human monitoring; System predictions } \\
\text { expected escape routes; System fast notifications to } \\
\text { police's mobile devices; Minimizes the crime rate and } \\
\text { further costs. } \\
\text { Preventive maintenance system: } \\
\text { Minimize flight delays, customer complaints, and major } \\
\text { accidents; Remote monitoring services; Preventive } \\
\text { maintenance service and eliminates potential threats; } \\
\text { Charged as per use. } \\
\text { Remote electronics control service: } \\
\text { Home Chat facility; Enables to handle home appliances } \\
\text { remotely }\end{array}$ & $\begin{array}{l}\text { Data management } \\
\text { issue, can handle } \\
\text { limited number of } \\
\text { devices }\end{array}$ \\
\hline $\begin{array}{l}\text { E-Marketing / smart } \\
\text { marketing [51] }\end{array}$ & $\begin{array}{l}\text { GPS } \\
\text { Credit cards }\end{array}$ & $\begin{array}{l}\text { Data mining } \\
\text { Database } \\
\text { Management } \\
\text { system }\end{array}$ & $\begin{array}{l}\text { The return on investment (ROI) is quick; Customer } \\
\text { experience improved; Easy Exchange of Sales Data; } \\
\text { Instant Customer Analysis; Intelligent Devices That } \\
\text { Know They’re Dying; Analytical Social Media; } \\
\text { Advertisements per interests/ preferences }\end{array}$ & $\begin{array}{l}\text { Privacy issues, } \\
\text { Lack of trust from } \\
\text { both sides } \\
\text { (customer \& } \\
\text { producer), } \\
\text { Destroying current } \\
\text { market }\end{array}$ \\
\hline Smart School [57] & $\begin{array}{l}\text { Varieties of } \\
\text { multimedia } \\
\text { equipment's } \\
\text { High-tech } \\
\text { instruments } \\
\text { Wireless network }\end{array}$ & Software & $\begin{array}{l}\text { Smart class: Integration of E-Learning environments } \\
\text { Smart card: e-attendance, access control, e-locker and e- } \\
\text { cash service } \\
\text { Smart information: provides intelligent information and } \\
\text { increased security } \\
\text { Smart management: Remotely monitors and control and } \\
\text { automated trouble warning. } \\
\text { High quality sharing } \\
\text { Enhance the quality of teaching materials }\end{array}$ & $\begin{array}{l}\text { Social effect as } \\
\text { due to emotions } \\
\text { attachments: } \\
\text { humans cannot be } \\
\text { replaced by } \\
\text { machines at some } \\
\text { places }\end{array}$ \\
\hline LittleBits [55] & $\begin{array}{l}\text { Nano Tech. } \\
\text { Sensors }\end{array}$ & Hardware & $\begin{array}{l}\text { No low level hardware or software details are needed } \\
\text { Facilitating beginner in development }\end{array}$ & Expensive \\
\hline Oracle Solaris 11 [54] [55] & $\begin{array}{l}\text { Virtual machines } \\
\text { OS } \\
\text { Physical domains } \\
\text { High level } \\
\text { connectivity }\end{array}$ & $\begin{array}{l}\text { Virtualization } \\
\text { Hardware } \\
\text { Software } \\
\text { Management } \\
\text { system } \\
\text { application }\end{array}$ & $\begin{array}{l}\text { Fulfill business needs } \\
\text { Increased efficiency } \\
\text { High availability } \\
\text { Elastic scalability } \\
\text { Rapid deployment, development \& management } \\
\text { Economic (Pay as You Go) } \\
\text { Low overhead \& Dynamic } \\
\text { Standard version and release of Oracle Solaris on all } \\
\text { zones }\end{array}$ & $\begin{array}{l}\text { Limited access } \\
\text { control, } \\
\text { Privacy \& } \\
\text { Security issue }\end{array}$ \\
\hline $\begin{array}{l}\text { Smart Manufacturing } \\
{[66]}\end{array}$ & $\begin{array}{l}\text { 3D printing } \\
\text { CAD or Scanning } \\
\text { machines }\end{array}$ & $\begin{array}{l}\text { Hardware } \\
\text { Software }\end{array}$ & $\begin{array}{l}\text { Cost effective manufacturing } \\
\text { Customizable and automatic } \\
\text { Time and energy saving } \\
\text { Variety of materials are available }\end{array}$ & $\begin{array}{l}\text { Intellectual } \\
\text { property rights and } \\
\text { criminal or illegal } \\
\text { use }\end{array}$ \\
\hline
\end{tabular}




\begin{tabular}{|c|c|c|c|c|}
\hline $\begin{array}{l}\text { Autonomous vehicles } \\
\text { [67] }\end{array}$ & $\begin{array}{l}\text { Sensors } \\
\text { Actuators } \\
\text { High-level } \\
\text { connectivity }\end{array}$ & $\begin{array}{l}\text { Real time } \\
\text { applications } \\
\text { Hardware } \\
\text { Database } \\
\text { management } \\
\text { system }\end{array}$ & $\begin{array}{l}\text { Minimize human errors that can occur while driving } \\
\text { Minimize death ratio or damages due to road accidents } \\
\text { A person can drive without driving knowledge }\end{array}$ & $\begin{array}{l}\text { Expensive, } \\
\text { environmental } \\
\text { changes effect } \\
\text { performance and } \\
\text { in case of } \\
\text { accident: who to } \\
\text { blame? }\end{array}$ \\
\hline $\begin{array}{l}\text { Driving Innovation in } \\
\text { Health Systems through an } \\
\text { Apps-Based Information } \\
\text { Economy } \\
{[68][69]}\end{array}$ & $\begin{array}{l}\text { APIs } \\
\text { Sensors } \\
\text { Actuators } \\
\text { GPS }\end{array}$ & $\begin{array}{l}\text { Database } \\
\text { management } \\
\text { system } \\
\text { Cyber-physical } \\
\text { systems }\end{array}$ & $\begin{array}{l}\text { APIs for cost effective health monitoring apps } \\
\text { development (FHIR API, SMART API, Research Kit, } \\
\text { Health Kit, Google Fit API, Validic API, 2net Platform, } \\
\text { etc }\end{array}$ & Inter-operability \\
\hline $\begin{array}{l}\text { Emergency alert and } \\
\text { communication } \\
\text { system[10][71] }\end{array}$ & $\begin{array}{l}\text { Sensors } \\
\text { Actuators } \\
\text { Data analytics }\end{array}$ & $\begin{array}{l}\text { Mobile apps } \\
\text { Augmented } \\
\text { realties } \\
\text { Hardware } \\
\text { Management } \\
\text { software }\end{array}$ & $\begin{array}{l}\text { Improve relationship between public and private } \\
\text { agencies } \\
\text { Provide emergency reaction teaching to all employees, } \\
\text { not just security workers } \\
\text { Manage mechanism and authorizations with secure } \\
\text { failover systems }\end{array}$ & $\begin{array}{l}\text { Standardization } \\
\text { and expensive }\end{array}$ \\
\hline $\begin{array}{l}\text { Smarter Highways variable } \\
\text { speed limits [72][73] }\end{array}$ & $\begin{array}{l}\text { Sensors } \\
\text { actuators } \\
\text { Data analytics }\end{array}$ & $\begin{array}{l}\text { Real time } \\
\text { application } \\
\text { Cyber-physical } \\
\text { devices }\end{array}$ & $\begin{array}{l}\text { Automatic sensing } \\
\text { Adjustable speed limits }\end{array}$ & $\begin{array}{l}\text { Weather effects } \\
\text { may affect the } \\
\text { sensing }\end{array}$ \\
\hline $\begin{array}{l}\text { Smart Farming } \\
{[9],[74]-[76]}\end{array}$ & $\begin{array}{l}\text { Data analytics } \\
\text { sensors }\end{array}$ & $\begin{array}{l}\text { Real time } \\
\text { application } \\
\text { Cyber-physical } \\
\text { devices }\end{array}$ & $\begin{array}{l}\text { Increase productivity } \\
\text { Reduce cost and economic } \\
\text { Provide notifications before alarming situations }\end{array}$ & expensive \\
\hline $\begin{array}{l}\text { Wearable devices } \\
\text { [77] }\end{array}$ & $\begin{array}{l}\text { Data monitoring apps } \\
\text { Sensors }\end{array}$ & $\begin{array}{l}\text { Ubiquities } \\
\text { computing } \\
\text { Virtualization } \\
\text { Hardware }\end{array}$ & $\begin{array}{l}\text { Body stabilizers e.g., Kokoon in-ear sleep headphones } \\
\text { High quality stimulated gaming } \\
\text { Lifesaving monitoring } \\
\text { Remote monitoring for pets } \\
\text { Health alarming }\end{array}$ & expensive \\
\hline
\end{tabular}

The marketers experienced rapid increase in their sales by using E-Marketing [58]. It is beneficial for both service providers and customers. In E-marketing/smart marketing [59], High-level connectivity using GPS etc. are used. The return on investment (ROI) from E-Marketing can go beyond that of traditional marketing strategies and customer experience improved increasingly. The key features include easy exchange of sales data, Smarter CRM (customer relationship management) with instantaneous customer analysis, Intelligent Devices "That Know They're Dying” with their own regular maintenance and diagnostics, predictive social media for customer preferences or demands and $100 \%$ CTR (Click through Rate) with no phishing of advertisements. Instead, not only consumer will be saved from time wasting on irrelevant ads but service providers will also be facilitated by avoiding wasting of money on irrelevant ads.

Many other useful developments are in progress in a rapid speed. The top IT enterprises are in competition to achieve more market value in the IoT development race. In future, the IoT is more predictable to take over lives with its innovations.

\section{THE IOT NECESSITIES}

In previous section, the recent technological advancements towards the IoT have been analyzed. Table I is providing brief analysis to these recent advancements while considering the related restrictions. By observing Table I, one can get an initial idea about the progress of the IoT and limitations. On the basis of Table I and II; it has been evaluated that the six key factors are necessary to deploy the Service-oriented Internet of Things. Four key factors to deploy the future
Internet: Smart Devices, Advanced Networks, Cloud Computing and Big Data Analytics are already been described in [55]. However, the two most critical factors: Security and Standardization/Policies cannot be ignored. Therefore, this paper analyzes and refine the major key factors to the necessities of the IoT in Figure 6.

The technology advancement analyzed in these areas has improved energy consumption by $50 \%$ and increased the battery life by $50 \%$ [55]. That ultimately decreases the cost factor involved and rate of errors occurrence. The most important and huge impacts of the IoT on daily life has been analyzed by [53] is that the IoT is replacing jobs and it is switching the whole industrial structure. In Table 1, the technological progressions and their effects are analyzed. The advantages in the IoT world has several associated challenges whereas, the six basic principles for deploying the IoT has been highlighted in Figure 6

\section{PERFORMANCE EVALUATION}

The paper aimed to analyzing all the papers, books and articles for technical constraints from 2009 onwards. This section provides the tabular summary of recent research advancements. Table II presents the most stressed technical limitations of the IoT. Table II is made on the focus or requirements of the IoT and the technical constraints claimed by the recent researchers. Moreover, it provides a comprehensive summary of all the technical requirements and associated challenges currently being faced by the IoT. It will be helpful for all of the domain individuals related to directly or indirectly IoT. 
TABLE II. COMPREHENSIVE OVERVIEW ABOUT TECHNICAL CHALLENGES OF THE IOT

\begin{tabular}{|c|c|c|c|}
\hline IoT requirements & Technical challenges & IoT requirements & Technical challenges \\
\hline $\begin{array}{l}\text { Organizational } \\
\text { Interoperability [45] }\end{array}$ & - Standards & $\begin{array}{l}\text { Organizational } \\
\text { Interoperability [44] }\end{array}$ & - Standards \\
\hline E-governance [43] & $\begin{array}{l}\text { - Semantic interoperability } \\
\text { - Syntactic interoperability } \\
\text { - Organizational interoperability } \\
\text { - Technical Interoperability } \\
\end{array}$ & {$[13]$} & $\begin{array}{l}\text { - Need efficient and interoperable solutions } \\
\text { - Cloud-based back end services } \\
\text { - Adaptable and dynamic analytics solutions }\end{array}$ \\
\hline [8] & $\begin{array}{l}\text { - Network and security foundation } \\
\text { - Size and scale of IoT providers }\end{array}$ & {$[6]$} & $\begin{array}{l}\text { - Privacy, Identity Management, Security and Access } \\
\text { control } \\
\text { - Standardization and Interoperability } \\
\text { - Data deluge } \\
\end{array}$ \\
\hline Smart devices [20] & $\begin{array}{l}\text { - Scalability } \\
\text { - "Arrive and operate" } \\
\text { - Interoperability } \\
\text { - Discovery } \\
\text { - Software complexity } \\
\text { - Data volumes } \\
\text { - Data interpretation } \\
\text { - Security and personal privacy } \\
\text { - Fault tolerance } \\
\text { - Power supply } \\
\text { - Interaction and short-range } \\
\text { - } \text { communications } \\
\text { - Wireless communications }\end{array}$ & [9] & $\begin{array}{l}\text { - Identification Technology } \\
\text { - Internet of Things Architecture Technology } \\
\text { - Communication Technology } \\
\text { - Network Technology } \\
\text { - Software } \\
\text { - Services and Algorithms } \\
\text { - Hardware } \\
\text { - Data and Signal Processing Technology } \\
\text { - Discovery and Search Engine Tech. } \\
\text { - Relationship Network Management Tech. } \\
\text { - Power and Energy Storage Tech. } \\
\text { - Security and Privacy Technologies } \\
\text { - Standardization }\end{array}$ \\
\hline $\begin{array}{l}\text { Internet Protocol } \\
\text { Wireless Sensor } \\
\text { Network [19] }\end{array}$ & $\begin{array}{l}\text { - IPV6 Adaptation } \\
\text { - Mobility } \\
\text { - Web-Enablement } \\
\text { - Time synchronization } \\
\text { - Security } \\
\text { - No efficient communication } \\
\text { protocol }\end{array}$ & IoT middleware [10] & $\begin{array}{l}\text { - Open issue Standards } \\
\text { - Mobility support Naming Transport protocol } \\
\text { - Traffic characterization and QoS support } \\
\text { - Authentication Data Integrity, Privacy, Digital } \\
\text { forgetting }\end{array}$ \\
\hline [49] & $\begin{array}{l}\text { - Heterogeneity and Scalability } \\
\text { - Security and Privacy } \\
\text { - Search and Discovery } \\
\text { - Ambient Intelligence }\end{array}$ & {$[21]$} & $\begin{array}{l}\text { - Identification and Addressing } \\
\text { - Internet scalability } \\
\text { - Heterogeneity } \\
\text { - Service Paradigms }\end{array}$ \\
\hline $\begin{array}{l}\text { IP smart objects and } \\
\text { Service composition } \\
{[78]}\end{array}$ & $\begin{array}{l}\text { - Recursiveness } \\
\text { - Semantic composition } \\
\text { - Context-awareness } \\
\text { - Hybrid composition } \\
\text { - Privacy and security } \\
\text { - Resource constraint } \\
\text { - Power efficiency } \\
\text { - Low-power \& Lossy } \\
\text { communication link } \\
\text { - Data/event-driven services } \\
\text { - Asynchrony } \\
\text { - Discovery } \\
\text { - Management requirements } \\
\text { - QoS awareness }\end{array}$ & $\begin{array}{l}\text { Cultural, ethical, } \\
\text { socio-economic, but } \\
\text { also technological } \\
\text { expectations in- } \\
\text { formation } \\
\text { communication } \\
\text { system [22] }\end{array}$ & $\begin{array}{l}\text { - Processing and Handling Limitations } \\
\text { - Storage Limitations } \\
\text { - Transmission Limitations } \\
\text { - Control Limitations } \\
\text { - Traffic growth vs heterogeneity in capacity distribution } \\
\text { - The current inter-domain routing system is reaching } \\
\text { fundamental limits } \\
\text { - Scaling to deal with flash crowding } \\
\text { - Significant processing power / storage / bandwidth for } \\
\text { indexing / crawling and (distributed) querying } \\
\text { - Security of the whole Internet Architecture } \\
\text { - Support of mobility }\end{array}$ \\
\hline $\begin{array}{l}\text { Smart home and smart } \\
\text { building systems [26] }\end{array}$ & $\begin{array}{l}\text { - Distributor-centric rather than } \\
\text { customer-centric } \\
\text { - Scalability }\end{array}$ & $\begin{array}{l}\text { Circuits and Systems } \\
{[25]}\end{array}$ & $\begin{array}{l}\text { - Low power consumption } \\
\text { - Highly modular approach } \\
\text { - Diversity }\end{array}$ \\
\hline [11] & $\begin{array}{l}\text { - Standardization issue } \\
\text { - Privacy and security issue } \\
\text { - Routing protocol issue in V2V } \\
\text { communication } \\
\text { - Addressing and networking issue } \\
\text { - Congestion and overload issue }\end{array}$ & $\begin{array}{l}\text { Internal security and } \\
\text { end-to-end user } \\
\text { transparency [24] }\end{array}$ & - IPV6 transition \\
\hline $\begin{array}{l}\text { SmartCities, WSNs \& } \\
\text { M2M (constraint } \\
\text { devices: low } \\
\text { computation power, } \\
\text { energy, memory)[7] }\end{array}$ & $\begin{array}{l}\text { - Scalability } \\
\text { - Governance } \\
\text { - Lack of testbeds } \\
\text { - Non-Interoperable solutions } \\
\text { - No efficient new communication } \\
\text { paradigm }\end{array}$ & {$[13]$} & $\begin{array}{l}\text { - Need efficient and interoperable solutions } \\
\text { - Cloud-based back end services } \\
\text { - Adaptable and dynamic analytics solutions }\end{array}$ \\
\hline Interoperability [47] & - Semantic interoperability & Light-weight IoT & - Semantic Interoperability \\
\hline
\end{tabular}




\begin{tabular}{|c|c|c|c|}
\hline & $\begin{array}{l}\text { - Syntactic interoperability } \\
\text { - Organizational interoperability } \\
\text { - Technical Interoperability }\end{array}$ & $\begin{array}{l}\text { reference architecture } \\
{[17]}\end{array}$ & $\begin{array}{l}\text { - Syntactic Interoperability } \\
\text { - Technical Interoperability } \\
\text { - Organizational Interoperability }\end{array}$ \\
\hline cloud computing [35] & - Security and cloud computing & M2M standards [28] & $\begin{array}{l}\text { - Standardization } \\
\text { - Interoperability }\end{array}$ \\
\hline $\begin{array}{l}\text { Application and usage } \\
\text { [32] }\end{array}$ & $\begin{array}{l}\text { - Privacy and security } \\
\text { - Standardization }\end{array}$ & Internetworking [27] & $\begin{array}{l}\text { - Congestion Control \& Resource Allocation } \\
\text { - Network Security }\end{array}$ \\
\hline $\begin{array}{l}\text { Smart environments } \\
{[79]}\end{array}$ & - Standardization and policies & $\begin{array}{l}\text { Device and data } \\
\text { security [40] }\end{array}$ & $\begin{array}{l}\text { - Nano-electronics } \\
\text { - Devices secure management } \\
\text { - Security algorithms }\end{array}$ \\
\hline [80] & $\begin{array}{l}\text { - Device and Data Security } \\
\text { - centralized Service Management } \\
\text { System(SMS) } \\
\text { - secure remote management }\end{array}$ & RFID tech. [42] & $\begin{array}{l}\text { - RFID technology transference to paper or plastic while } \\
\text { holding the required productive resolution }\end{array}$ \\
\hline [46] & $\begin{array}{l}\text { - standardization and } \\
\text { synchronization } \\
\text { - Privacy } \\
\text { - Pervasive and Trustworthy } \\
\text { Network and Service } \\
\text { Infrastructures } \\
\text { - Nanotechnologies, sensor } \\
\text { technologies, solutions bridging } \\
\text { Nano and micro systems, etc. } \\
\text { - Components, Systems, } \\
\text { Engineering } \\
\text { - Towards sustainable \& } \\
\text { personalized healthcare } \\
\text { - Mobility, Environmental } \\
\text { Sustainability \& Energy Efficiency } \\
\text { - Independent Living, Inclusion \& } \\
\text { Governance }\end{array}$ & Interoperability [29] & $\begin{array}{l}\text { - Convergence in Technology } \\
\text { - Integration of multiple data-sources } \\
\text { - Unified Data Map / Ontology as point of reference } \\
\text { - Mobility and Crowd sensing } \\
\text { - P2P Communication } \\
\text { - Data Modeling and Data Exchange } \\
\text { - Ontology merging / Ontology matching \& alignment } \\
\text { - Data/Event Semantic Annotation } \\
\text { - Knowledge Representation \& related ontologies } \\
\text { - Knowledge Sharing } \\
\text { - Knowledge Revision \& Consistency } \\
\text { - Semantic Discovery of Data Sources, Data and } \\
\text { - Services } \\
\text { - Semantic Publish/subscribe \& Semantic Routing } \\
\end{array}$ \\
\hline $\begin{array}{l}\text { Plug n' Play smart } \\
\text { objects [12] }\end{array}$ & $\begin{array}{l}\text { - Complete Architecture } \\
\text { - Efficient energy sensing } \\
\text { - Secure reprogrammable networks } \\
\text { and privacy } \\
\text { - Quality of service (QoS) } \\
\text { management } \\
\text { - New protocols } \\
\text { - Participatory sensing } \\
\text { - Data mining for deep learning in } \\
\text { terms of the need for adaptive, } \\
\text { distributed and incremental } \\
\text { learning techniques } \\
\text { - GIS based visualization }\end{array}$ & $\begin{array}{l}\text { Enabling } \\
\text { technologies, Nano } \\
\text { electronics, cyber } \\
\text { physical systems, } \\
\text { intelligent device } \\
\text { management, smart } \\
\text { gateways, telematics, } \\
\text { smart network } \\
\text { infrastructure, cloud } \\
\text { computing, ecosystem } \\
\text { and industrial } \\
\text { applications [31] }\end{array}$ & $\begin{array}{l}\text { - Security } \\
\text { - Reliability } \\
\text { - Complex integration } \\
\text { - Discoverability } \\
\text { - Interoperability } \\
\text { - Standardization } \\
\text { - High data rates } \\
\text { - Dense crowds of users } \\
\text { - Low latency } \\
\text { - Low energy and } \\
\text { - Low cost } \\
\text { - A massive number of devices } \\
\text { - Design of open APIs }\end{array}$ \\
\hline $\begin{array}{l}\text { Business view of IoT } \\
\text { [51] }\end{array}$ & $\begin{array}{l}\text { - Privacy, security and } \\
\text { confidentiality } \\
\text { - Standards } \\
\text { - scalability }\end{array}$ & $\begin{array}{l}\text { IoT Business and } \\
\text { cloud computing [33] }\end{array}$ & $\begin{array}{l}\text { - Standardization } \\
\text { - Autonomic capabilities } \\
\text { - Data operations } \\
\text { - Privacy protection }\end{array}$ \\
\hline [81] & $\begin{array}{l}\text { - Heterogeneous and resource } \\
\text { constrained devices } \\
\text { - LLN(low power and lossy } \\
\text { Network) } \\
\text { - Confidentiality, mutual } \\
\text { authentication \& message origin } \\
\text { authentication } \\
\text { - Security protocols }\end{array}$ & $\begin{array}{l}\text { Warehousing or } \\
\text { future supply chain } \\
\text { management [37] }\end{array}$ & $\begin{array}{l}\text { - Integration } \\
\text { - Agility } \\
\text { - Consolidation } \\
\text { - ROI } \\
\text { - Standardization } \\
\text { - performance guarantees and manager trust }\end{array}$ \\
\hline $\begin{array}{l}\text { Open systems for IoT } \\
\text { [48] }\end{array}$ & $\begin{array}{l}\text { - Data integration } \\
\text { - Data automation } \\
\text { - Data analyzation for identifying } \\
\text { - Sctionable insights } \\
\text { - Scalability } \\
\text { - Anteroperability } \\
\text { - Agility } \\
\end{array}$ & $\begin{array}{l}\text { Context-aware } \\
\text { deployment of IoT } \\
{[36]}\end{array}$ & $\begin{array}{l}\text { - Automated configuration of sensors } \\
\text { - Context discovery } \\
\text { - Acquisition, modelling, reasoning, \& distribution } \\
\text { - Selection of sensors in sensing-as-a-service model } \\
\text { - Security, privacy, and trust } \\
\text { - Context Sharing }\end{array}$ \\
\hline Security [52] & $\begin{array}{l}\text { - Identification/ authentication } \\
\text { - Trust } \\
\text { - Reliability } \\
\text { - Auto-immunity }\end{array}$ & {$[50]$} & $\begin{array}{l}\text { - Bootstrapping } \\
\text { - Mobility } \\
\text { - Scalability } \\
\text { - Data processing } \\
\end{array}$ \\
\hline
\end{tabular}




\begin{tabular}{|c|c|c|c|}
\hline & $\begin{array}{l}\text { - Privacy } \\
\text { - Responsibility } \\
\text { - Safety }\end{array}$ & & $\begin{array}{l}\text { - Standardization } \\
\text { - Protocol and network security } \\
\text { - Data and privacy } \\
\text { - Identity management } \\
\text { - Trust and governance } \\
\text { - Fault tolerance } \\
\end{array}$ \\
\hline$[82]$ & $\begin{array}{l}\text { - Security and privacy } \\
\text { - Mobility management } \\
\text { - QoS support } \\
\text { - Protocols (at both network and } \\
\text { transport layer) } \\
\text { - Energy limitation and efficiency }\end{array}$ & [83] & $\begin{array}{l}\text { - } \text { self-describable and self-contained } \\
\text { - } \text { privacy and security } \\
\text { - limited power supply } \\
\text { - } \text { communication interoperability } \\
\text { - } \text { semantic interoperability } \\
\text { - syntactic interoperability }\end{array}$ \\
\hline Business model [39] & - Devices Integration & IoT ecosystem [18] & - IoT business models and standards \\
\hline Security [84] & $\begin{array}{l}\text { - Routing protocol } \\
\text { - Identity management framework }\end{array}$ & & \\
\hline
\end{tabular}

\section{Ratio of devices}

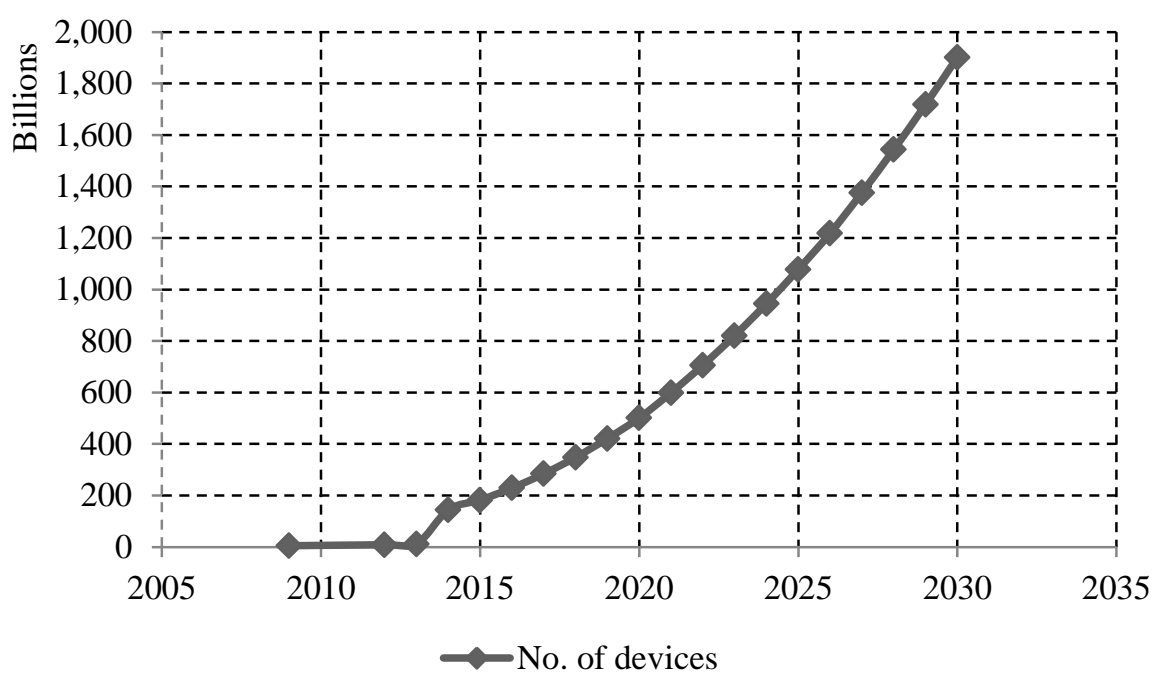

Fig. 7. Number of devices (in billions) per year

TABLE III. Number of DeVICES (IN BILlions) Per Year

\begin{tabular}{|l|l|}
\hline Year & $\begin{array}{l}\text { No. of devices in } \\
\text { Billion }\end{array}$ \\
\hline 2009 & 4.8 \\
\hline 2012 & 8.7 \\
\hline 2013 & 11.2 \\
\hline 2014 & 144 \\
\hline 2015 & 182 \\
\hline 2016 & 229 \\
\hline 2017 & 284 \\
\hline 2018 & 348 \\
\hline 2019 & 421 \\
\hline 2020 & 501 \\
\hline 2021 & 599 \\
\hline 2022 & 706 \\
\hline 2023 & 821 \\
\hline 2024 & 945 \\
\hline 2025 & 1,078 \\
\hline 2026 & 1,218 \\
\hline 2027 & 1,376 \\
\hline 2028 & 1,543 \\
\hline 2029 & 1,718 \\
\hline 2030 & 1,902 \\
\hline
\end{tabular}




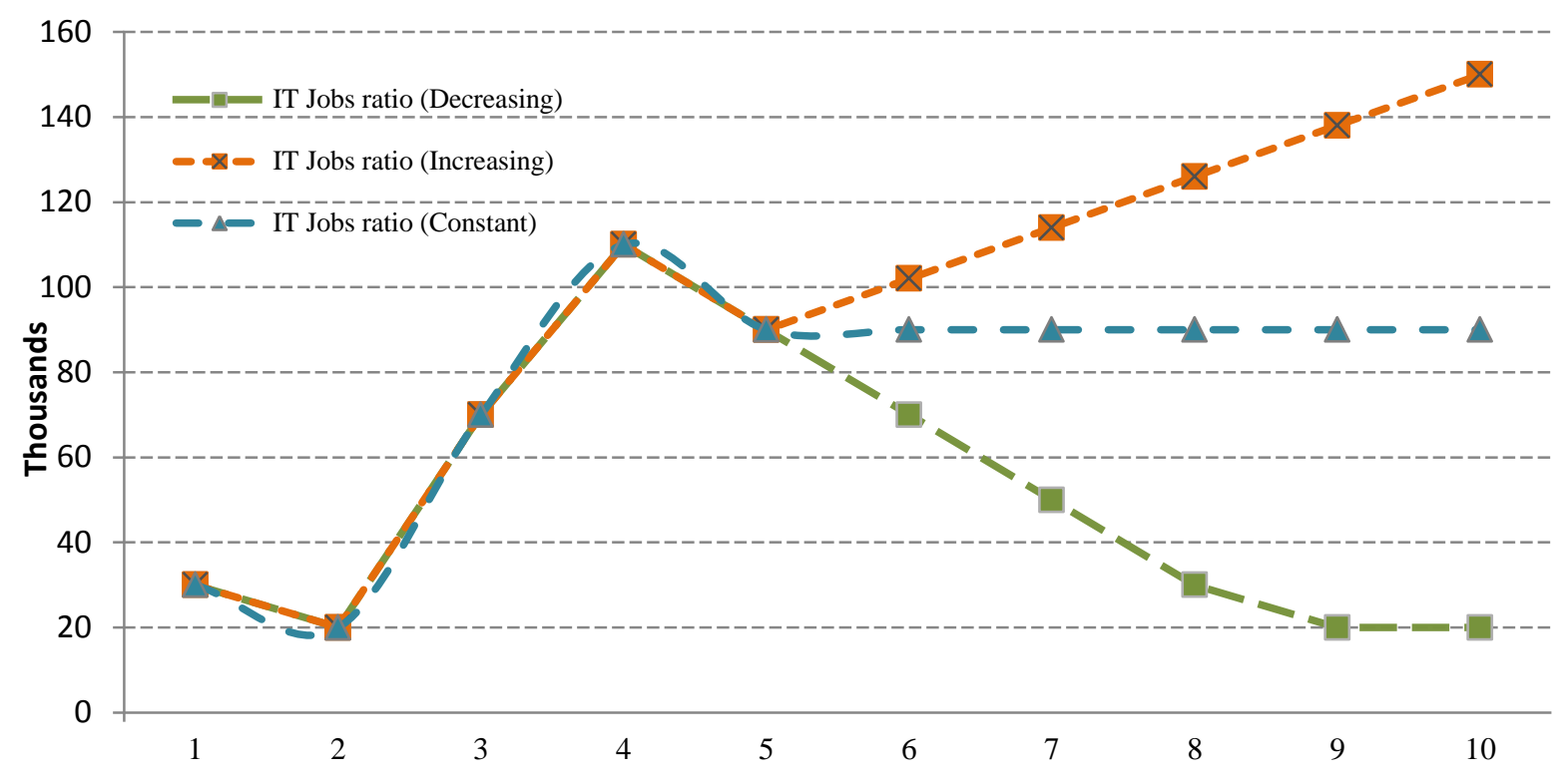

Fig. 8. Estimated number of IT jobs per year from 2011 to 2020

\section{THE WORLD IN 2020 AND BEYOND}

By analyzing details in previous sections, it can be concluded that the IoT is important enough to change the way of living and even the whole world. The technical constraints analyzed in this paper are the most important and critical ones. These technical constraints are key factors for the future Internet and can enormously affect cost factor for the future devices and technology. The affect the social life style and the way of living in many perspectives will be greatly influenced. An IT research company, Gartner; estimated the human resource demand will be reduced up to $50 \%$ by 2018 due to the intelligent machines technology advancements. With the high-speed development in the IoT and its job formation effect, Digital Business related jobs are also predicted to grow up $50 \%$. Repetitive and life-critical work can be replaced by the IoT services. Moreover, Automation functionalities as a key feature of the IoT made it possible to take over data analysis. The industrial structure is creating new values by changing the whole infrastructure and destroying the traditional system revenues. Enterprise value of Uber was analyzed as $\$ 45$ billion in December of 2014. The Wall Street Journal has analyzed the abrupt growth and estimated it to be $\$ 50$ billion in May of 2015. The opportunity of existing industrial dominators could be threatened by novel outstanding ideas' innovators, is getting higher.
TABLE IV. Number of Jobs (IN Number) Per Year

\begin{tabular}{|l|l|l|l|}
\hline Year & $\begin{array}{l}\text { IT Jobs ratio } \\
\text { (Decreasing) }\end{array}$ & $\begin{array}{l}\text { IT Jobs ratio } \\
\text { (Constant) }\end{array}$ & $\begin{array}{l}\text { IT Jobs ratio } \\
\text { (Increasing) }\end{array}$ \\
\hline 2011 & 30000 & 30000 & 30000 \\
\hline 2012 & 20000 & 20000 & 20000 \\
\hline 2013 & 70000 & 70000 & 70000 \\
\hline 2014 & 110000 & 110000 & 110000 \\
\hline 2015 & 90000 & 90000 & 90000 \\
\hline 2016 & 70000 & 90000 & 102000 \\
\hline 2017 & 50000 & 90000 & 114000 \\
\hline 2018 & 30000 & 90000 & 126000 \\
\hline 2019 & 20000 & 90000 & 138000 \\
\hline 2020 & 20000 & 90000 & 150000 \\
\hline
\end{tabular}

If the ratio of devices connectivity is closely observed up to year: 2020 then the number of devices in next year's up to 2026 can be estimated. Figure 7 shows the prediction on the common increasing ratio among previous years' estimations. However, the Table III shows the statistics for assumptions of this paper; the gray shading color highlights the calculated assumptions. Indirectly, the number of devices per year is affecting the number of IT jobs per year. In contrast, the IT jobs are not completely down falling but their average value is not increasing as well. Figure 8 demonstrates the estimated ratio of IT jobs over years. It can be increasing, decreasing or constant amount of IT jobs according to the observation of 
previous years' ratio. Overall analysis for the future Internet era clearly delivers the fact that successful companies or organizations will be those, who will provide some innovative technological ideas. The others will be just doomed out economically.

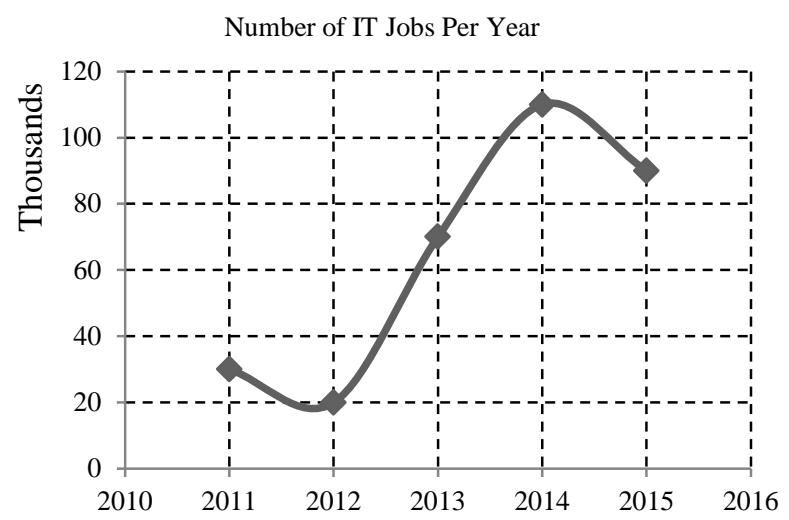

Fig. 9. Number of jobs (in number) per year

The statistical data obtained from [60] shows the number of IT jobs in recent years (up to 2015). The data has been analyzed to estimate the ratio of IT jobs in future (up to 2020). The aforesaid ratio has been plotted in Figure 9 whereas, Table IV shows the statistics. The three variations of IT jobs in Figure 9 shows the three assumptions for increasing (highlighted by green color), decreasing (highlighted by orange color) or constant rate (highlighted by green color) of IT jobs. These assumptions are being calculated on average ratios of recent years. The quick analysis of IT jobs against advancement in IT shows that average rate of IT jobs is down falling and not increasing with the rate of the IoT advancements. The reason behind down falling of IT jobs are vague but can be justified by keenly analyzing technology advancements. With the rapid growth in automation and artificial intelligence properties in industries eventually minimizing the human resource factor needed to operate and maintain the environments. The industrialization became more successful entity as compare to other government level jobs. That results in privatization effect, which ultimately goals more work with fewer jobs.

Another major factor involved for discussed downfall is the increased ratio of population. Moreover, young and educated people belong from urban areas or less developed areas moves to rural or developed areas. This ultimately increases the competition for better opportunities as per the life standard are changed. The IoT as advancement in technology is also playing major role in changing life standards of society.

\section{CONCLUSION}

The concept of the IoT is maturing rapidly and soon we will be seeing the world-wide interconnected network, integrating every physical device with other devices. The IoT has been focused exhaustively in recent years due to its wider applications such as eliminating space, reducing cost, saving energy and intensive monitoring. This paper highlighted the core areas of the IoT and specifically targeted the technical constraints that act as critical hurdle in the way to deploy the successful IoT infrastructure. We categorized these challenges in security, hardware, standards, gateway systems, middleware and the IoT databases etc. Open issues to the IoT are also enlightened that are required to be addressed by the researchers and other stakeholders of the IoT. Moreover, our future predictions will help the concerned parties to prepare for the IoT accordingly. In future, we aim to provide solutions about the open issues to the IoT.

\section{REFERENCES}

[1] S. N. Han, I. Khan, G. Myoung, N. Crespi, and R. H. Glitho, "Computer Standards \& Interfaces Service composition for IP smart object using realtime Web protocols: Concept and research challenges," Comput. Stand. Interfaces, vol. 43, pp. 79-90, 2016.

[2] CompTIA, "Sizing Up the Internet of Things," 2015.

[3] Swan, "Sensor Mania! The Internet of Things, Wearable Computing, Objective Metrics, and the Quantified Self 2 . 0," J. Sens. Actuator Networks, pp. 217-253, 2012.

[4] S. Taylor, "How service providers can help businesses to realize the promise of the IoT revolution," CISCO, 2016. [Online]. Available: http://blogs.cisco.com/sp/how-service-providers-can-help-businesses-torealize-the-promise-of-the-iot-revolution\#more-185149. [Accessed: 09Oct-2016].

[5] Bauer, M. Boussard, N. Bui, F. (UniS) Carrez, C. (SIEMENS) Jardak, J. (ALUBE) De Loof, C. (SAP) Magerkurth, S. Meissner, A. (FhG I. Nettsträter, A. (CEA) Olivereau, M. (SAP) Thoma, W. W. Joachim, J. (CSD/SUni) Stefa, and A. (UniWue) Salinas, "Internet of Things Architecture IoT-A Deliverable D1 . 5 - Final architectural reference model for the IoT v3 . 0," 2013.

[6] L. Coetzee and J. Eksteen, "The Internet of Things - Promise for the Future? An Introduction,” IST-Africa Conf. Proc., pp. 1-9, 2011.

[7] Elmangoush, H. Coskun, S. Wahle, and T. Magedanz, "Design aspects for a reference M2M communication platform for Smart Cities," in 2013 9th International Conference on Innovations in Information Technology (IIT), 2013, pp. 204-209.

[8] Lopez Research, "An Introduction to the Internet of Things (IoT)," Lopez Res. Llc, vol. Part 1. of, no. November, pp. 1-6, 2013.

[9] H. Sundmaeker, P. Guillemin, and P. Friess, Vision and challenges for realising the Internet of Things, no. March. 2010.

[10] L. Atzori, A. Iera, and G. Morabito, "The Internet of Things: A survey," Comput. Networks, vol. 54, no. 15, pp. 2787-2805, 2010.

[11] S. Agrawal and D. Vieira, "A Survey on Internet of Things: Security and Privacy Issues," Abakós, vol. 1, pp. 78-95, 2013.

[12] J. Gubbi, R. Buyya, S. Marusic, and M. Palaniswami, "Internet of Things (IoT): A vision, architectural elements, and future directions," Futur. Gener. Comput. Syst., vol. 29, no. 7, pp. 1645-1660, 2013.

[13] P. Barnaghi and A. Sheth, "Internet of Things: The Story So Far," 2014.

[14] Brandon Butler, "12 most powerful Internet of Things companies | Network World," 2014. [Online]. Available: http://www.networkworld.com/article/2287045/wireless/153629-10most-powerful-Internet-of-Things-companies.html. [Accessed: 17-Dec2015].

[15] Skerrett, "How to Categorize the Internet of Things - DZone IoT." [Online]. Available: https://dzone.com/articles/how-categorize-internetthings. [Accessed: 16-Dec-2015].

[16] Gigli, "Internet of Things: Services and Applications Categorization," Adv. Internet Things, vol. 1, no. 2, pp. 27-31, 2011.

[17] S. Bandyopadhyay, P. Balamuralidhar, and A. Pal, "Interoperation among IoT Standards," J. ICT Stand., vol. 1, no. 2, pp. 253-270, 2013.

[18] S. Leminen, M. Westerlund, M. Rajahonka, and R. Siuruainen, "Towards IOT ecosystems and business models," Lect. Notes Comput. Sci. (including Subser. Lect. Notes Artif. Intell. Lect. Notes Bioinformatics), vol. 7469 LNCS, pp. 15-26, 2012.

[19] G. Deak, K. Curran, J. Condell, E. Asimakopoulou, and N. Bessis, "IoTs (Internet of Things) and DfPL (Device-free Passive Localisation) in a 
disaster management scenario," Simul. Model. Pract. Theory, vol. 35, no. October 2015, pp. 86-96, 2013.

[20] F. Mattern and C. Floerkemeier, "From the internet of computers to the internet of things," Lect. Notes Comput. Sci. (including Subser. Lect. Notes Artif. Intell. Lect. Notes Bioinformatics), vol. 6462 LNCS, pp. 242-259, 2010.

[21] S. Haller, S. Karnouskos, and C. Schroth, "The Internet of things in an enterprise context," Lect. Notes Comput. Sci. (including Subser. Lect. Notes Artif. Intell. Lect. Notes Bioinformatics), vol. 5468, pp. 14-28, 2009.

[22] H. Schaffers, A. Sallstrom, M. Pallot, J. M. Hernandez-Munoz, R. Santoro, B. Trousse, J. Domingue, A. Galis, A. Gavras, T. Zahariadis, D. Lambert, F. Cleary, P. Daras, S. Krco, H. Müller, M.-S. Li, and others, The Future Internet-Future Internet Assembly 2011: Achievements and Technological Promises. 2011.

[23] Stockebrand, "IPv6 Address Basics," in IPv6 in Practice: A Unixer's Guide to the Next Generation Internet, Berlin, Heidelberg: Springer Berlin Heidelberg, 2007, pp. 21-34.

[24] G. Han, C. Bao, X. Li, and S. Liu, "IPv6 Transition for the Other Billions," Comput. Commun. Networks (ICCCN), 2015 24th Int. Conf., 2015.

[25] Blaauw, D. Sylvester, P. Dutta, Y. Lee, I. Lee, S. Bang, Y. Kim, G. Kim, P. Pannuto, Y.-S. Kuo, D. Yoon, W. Jung, Z. Foo, Y.-P. Chen, S Oh, S. Jeong, and M. Choi, "IoT design space challenges: Circuits and systems," in 2014 Symposium on VLSI Technology (VLSITechnology): Digest of Technical Papers, 2014, pp. 1-2.

[26] Spano, L. Niccolini, S. Di Pascoli, and G. Iannacconeluca, "Last-Meter Smart Grid Embedded in an Internet-of-Things Platform," IEEE Trans. Smart Grid, vol. 6, no. 1, pp. 468-476, 2015.

[27] B. S. Peterson, Larry L and Davie, Computer Networks: A Systems Approach, 5th ed., 5th ed. Morgan Kaufmann, 2011.

[28] T. Klinpratum, C. Saivichit, A. Elmangoush, and T. Magedanz, "Performance of Interworking Proxy for Interconnecting IEEE1888 Standard at ETSI M2M Platforms," Appl. Mech. Mater., vol. 781, pp. 141-144, 2015.

[29] W. Pollard, IoT Semantic Interoperability: Research Challenges, Best Practices, Recommendations and Next Steps. IERC (European Research Cluster On The Internet Of Things), 2015.

[30] Microsoft Corporation, "Ten reasons your business needs a strategy to capitalize on the Internet of Things today," 2014.

[31] L. and others Medagliani, P and Leguay, J and Duda, Andrzej and Rousseau, Franck and Duquennoy, S and Raza, S and Ferrari, Gianluigi and Gonizzi, P and Cirani, S and Veltri, Internet of Things Applications - From Research and Innovation to Market Deployment. River Publishers, 2014.

[32] Chaouchi and Hakima, The Internet of Things: Connecting Objects. John Wiley \& Sons, 2013.

[33] S. Shen and M. Carug, "An EvolutionaryWay to Standardize the Internet of Things," J. ICT Stand., vol. 2, no. 2, pp. 87-108, 2014.

[34] H. Petersen, M. Lenders, M. Wählisch, O. Hahm, and E. Baccelli, “Old Wine in New Skins? Revisiting the Software Architecture for IP Network Stacks on Constrained IoT Devices," p. 6, Feb. 2015.

[35] J. Vanian, "Cisco CEO Chuck Robbins talks importance of the Internet of things - Fortune," 2015. [Online]. Available: http://fortune.com/2015/10/05/cisco-chuck-robbins-internet/. [Accessed: 15-Dec-2015].

[36] C. Perera, A. Zaslavsky, P. Christen, and D. Georgakopoulos, "Context Aware Computing for The Internet of Things: A Survey," vol. X, no. X, pp. 1-41, 2013.

[37] J. Reaidy, A. Gunasekaran, and A. Spalanzani, "Bottom-up approach based on Internet of Things for order fulfillment in a collaborative warehousing environment," Int. J. Prod. Econ., vol. 159, pp. 29-40, 2015.

[38] N. Meghanathan, S. Boumerdassi, N. Chaki, and D. Nagamalai, Eds., Recent Trends in Networ b k Security and Applications, vol. 89. Berlin, Heidelberg: Springer Berlin Heidelberg, 2010.

[39] TIMMS, "Monitoring 4.0: How to track the Internet of Things | Business Spectator," $2014 . \quad$ [Online]. http://www.businessspectator.com.au/article/2014/6/11/technology/moni toring-40-how-track-internet-things. [Accessed: 02-Dec-2015].

[40] S. David Lake, Ammar Rayes, and Monique Morrow, "The Internet of Things - The Internet Protocol Journal, Volume 15, No. 3," 2013. [Online]. Available: http://www.cisco.com/web/about/ac123/ac147/archived_issues/ipj_153/153_internet.html. [Accessed: 15-Dec-2015].

[41] "Subscriptions \& Rate Plans - Telit," 2015. [Online]. Available: http://www.telit.com/products-and-services/iotconnectivity/subscriptions-rate-plans/. [Accessed: 16-Dec-2015].

[42] Scd. E. Staff, "RFID and AIDC News: New Chipless RFID Tag Could Transform the Industry," 2015. [Online]. Available: http://www.scdigest.com/ontarget/15-04-22-1.php?cid=9228. [Accessed: 12-Dec-2015].

[43] H. Kubicek, R. Cimander, and H. J. Scholl, Organizational Interoperability in E-Government. Springer Science I\& Business Media, 2011.

[44] H. Gottschalk, Petter and Solli-Saether, "Levels of Organizational Interoperability," E-Government Interoperability Inf. Resour. Integr. Fram. Aligned Dev. IGI Glob. Philadelphia, PA, pp. 242-244, 2009.

[45] H. Kubicek and R. Cimander, "Three dimensions of organizational interoperability. [o.j] Insights from recent studies for improving interoperability frame-works," Eur. J. ePractice, no. January, pp. 1-12, 2009.

[46] Toma, E. Simperl, and G. Hench, A joint roadmap for semantic technologies and the internet of things, vol. 1, no. APRIL. 2009.

[47] Gottschalk and H. Solli-Sæther, E-Government Interoperability and Information Resource Integration. IGI Global, 2009.

[48] N. Noronha, Andy and Moriarty, R and Connell, KO and Villa, "Attaining IoT Value: How To Move from Connecting Things to Capturing Insights Gain an Edge by Taking Analytics to the Edge," Cisco Anal. Br., 2014.

[49] Zeng, S. Guo, and Z. Cheng, "The Web of Things: A Survey (Invited Paper)," J. Commun., vol. 6, no. 6, 2011.

[50] Roman, P. Najera, and J. Lopez, "Securing the Internet of things," Computer (Long. Beach. Calif)., vol. 44, no. 9, pp. 51-58, 2011.

[51] Uckelmann, M. Harrison, and F. Michahelles, "Architecting the Internet of Things," pp. 1-25, 2011.

[52] Riahi, Y. Challal, E. Natalizio, Z. Chtourou, and A. Bouabdallah, "A Systemic Approach for IoT Security," 2013 IEEE Int. Conf. Distrib. Comput. Sens. Syst., pp. 351-355, 2013.

[53] "What Can 'Things' do When Connected to 'The Internet'? -Talk Service-Oriented IoT(2)- | LG CNS Blog | Creative \& Smart.” [Online]. Available: http://www.lgcnsblog.com/features/what-can-things-dowhen-connected-to-the-internet-talk-service-oriented-iot2/. [Accessed: 16-Dec-2015].

[54] "Train keeping promises, smart rail system | GE reports Korea." [Online]. Available: http://www.gereports.kr/ge-trip-optimizer-forsmart-train-solution/. [Accessed: 17-Dec-2015].

[55] "What We Need to Implement IoT - Talk Service-Oriented IoT (3) - | LG CNS Blog | Creative \& Smart." [Online]. Available: http://www.lgcnsblog.com/features/what-we-need-to-implement-iottalk-service-oriented-iot-3/. [Accessed: 16-Dec-2015].

[56] "How to Get Started DIYing Anything with LittleBits." [Online]. Available: http://lifehacker.com/how-to-get-started-diying-anythingwith-littlebits-1617311793. [Accessed: 21-Dec-2015].

[57] "A Step Closer to Educational Equality with ICT and Smart Schools LG CNS Blog | Creative \& Smart." [Online]. Available: http://www.lgcnsblog.com/features/a-step-closer-to-educationalequality-with-ict-and-smart-schools/. [Accessed: 16-Dec-2015].

[58] "Advantages and disadvantages of online marketing." [Online]. Available: http://zeendo.com/info/advantages-and-disadvantages-ofonline-marketing/. [Accessed: 21-Dec-2015].

[59] Leung, "5 Ways the Internet of Things Will Make Marketing Smarter Salesforce Blog," 2014. [Online]. Available: https://www.salesforce.com/blog/2014/03/internet-of-things-marketingimpact.html. [Accessed: 17-Dec-2015]. 
[60] "Number of IT Jobs down." [Online]. Available: http://www.ejanco.com/Press/2015/2015-09-04-Forecast-New-IT-Jobs-Revised.html. [Accessed: 17-Dec-2015].

[61] Health and I. Portability, "SANS Institute InfoSec Reading Room," 2001.

[62] M. Rouse, "What is OSI reference model (Open Systems Interconnection)? - Definition from WhatIs.com," 2014. [Online]. Available: http://searchnetworking.techtarget.com/definition/OSI. [Accessed: 09-Oct-2016].

[63] C. Borysowich, "EA Deliverable: Architecture Strategy: Interoperability," 2008. [Online]. Available: http://it.toolbox.com/blogs/enterprise-solutions/ea-deliverablearchitecture-strategy-interoperability-sample-27850. [Accessed: 09-Oct2016].

[64] "Building a Cloud-Based Data Center with Oracle Solaris 11 - Part 1." [Online].

Available: http://www.oracle.com/technetwork/articles/servers-storageadmin/build-cloud-solaris11-2172575.html. [Accessed: 21-Dec-2015].

[65] Enterprise, O. Distribution, and N. Virtualization, "Oracle Solaris 11 Engineered for Cloud | Oracle."

[66] "Smart Manufacturing magazine to Launch in Spring 2016 -DEARBORN, Mich., Dec. 7, 2015 /PRNewswire-USNewswire/ --." [Online]. Available: http://www.prnewswire.com/news-releases/smartmanufacturing-magazine-to-launch-in-spring-2016-300188473.html. [Accessed: 25-Jan-2016].

[67] "CES 2016: Carmakers kick off the year with big moves in autonomous vehicles - TechRepublic." [Online]. Available: http://www.techrepublic.com/article/ces-2016-carmakers-kick-off-theyear-with-big-moves-in-autonomous-vehicles/. [Accessed: 25-Jan2016].

[68] K. D. Mandl, J. C. Mandel, and I. S. Kohane, "Driving Innovation in Health Systems through an Apps-Based Information Economy," Cell Syst., vol. 1, no. 1, pp. 8-13, Jun. 2015.

[69] "Internet of Things Examples - Postscapes." [Online]. Available: http://postscapes.com/internet-of-things-examples/. [Accessed: 25-Jan2016].

[70] "Overcoming Emergency Notification Challenges in 2016." [Online]. Available: http://www.everbridge.com/overcoming-emergencynotification-challenges-in-2016/. [Accessed: 25-Jan-2016].

[71] "AtHoc - Networked Crisis Communication." [Online]. Available: http://www.athoc.com/. [Accessed: 25-Jan-2016].
[72] "Smarter Highways variable speed limits." [Online]. Available: http://www.wsdot.wa.gov/smarterhighways/vsl.htm. [Accessed: 25-Jan2016].

[73] R. No and P. For, "Variable speed limit signs effects on speed and speed var i ation in work," no. January, 2008.

[74] "Reading Beehives: Smart Sensor Technology Monitors Bee Health and Global Pollination | Libelium." [Online]. Available: http://www.libelium.com/temperature-humidity-and-gases-monitoringin-beehives/. [Accessed: 25-Jan-2016].

[75] "Smart Farming: Monitoring Horses and Equine Facility Management with Waspmote | Libelium." [Online]. Available: http://www.libelium.com/smart-farming-monitoring-horses-equinefacility-management-waspmote. [Accessed: 25-Jan-2016].

[76] "Sustainable Farming and the IoT: Cocoa Research Station in Indonesia | Libelium." [Online]. Available: http://www.libelium.com/sustainablefarming-and-the-iot-cocoa-research-station-in-indonesia. [Accessed: 25Jan-2016].

[77] "50 wearable tech gamechangers for 2016." [Online]. Available: http://www.wareable.com/wareable50/best-wearable-tech. [Accessed: 25-Jan-2016].

[78] N. Han, I. Khan, G. M. Lee, N. Crespi, and R. H. Glitho, "Service Composition for IP Smart Object using Realtime Web Protocols: Concept and Research Challenges," Comput. Stand. Interfaces, vol. 43, pp. 79-90, Aug. 2015.

[79] William Pollard, Internet of Things: Pan European Research and Innovation Vision. IERC, 2011.

[80] Strom, "The Demise of Web 2.0 and Why You Should Care," Internet Protoc. J., vol. 15, no. 3, pp. 20-24, 2012.

[81] J. Park, S. Shin, and N. Kang, "Mutual Authentication and Key Agreement Scheme between Lightweight Devices in Internet of Things," vol. 38, no. 9, 2013.

[82] Iera, C. Floerkemeier, J. Mitsugi, and G. Morabito, "Guest Editorial: The internet of things," IEEE Wirel. Commun., no. December, pp. 8-9, 2010.

[83] M. Jazayeri, S. Liang, and C.-Y. Huang, "Implementation and Evaluation of Four Interoperable Open Standards for the Internet of Things," Sensors, vol. 15, no. 9, pp. 24343-24373, Sep. 2015.

[84] D. Meghanathan, Natarajan and Boumerdassi, Selma and Chaki, Nabendu and Nagamalai, Recent Trends in Network Security and Applications. Springer, 2010. 